*For correspondence:
mporfiri@nyu.edu (MP);
peterson@uwaterloo.ca (SDP)

\title{
. Hydrodynamic model of fish : orientation in a channel flow
}

3 Maurizio Porfiri ${ }^{1,2,3^{*}}$, Peng Zhang ${ }^{2,3}$, Sean D. Peterson ${ }^{4}$

$4{ }^{1}$ Department of Biomedical Engineering, New York University Tandon School of

5 Engineering; 370 Jay Street, 11201 Brooklyn (NY) - USA; ${ }^{2}$ Department of Mechanical and

- Aerospace Engineering, New York University Tandon School of Engineering; 370 Jay

7 Street, 11201 Brooklyn (NY) - USA; ${ }^{3}$ Center for Urban Science and Progress, New York

s University Tandon School of Engineering; 370 Jay Street, 11201 Brooklyn (NY) - USA;

- ${ }^{4}$ Mechanical and Mechatronics Engineering Department, University of Waterloo; 200

University Avenue West, Waterloo ON N2L 3 G1 - Canada

\begin{abstract}
For over a century, scientists have sought to understand how fish orient against an incoming flow, even without visual and flow cues. Here, we make an essential step to elucidate the hydrodynamic underpinnings of rheotaxis through the study of the bidirectional coupling between fish and the surrounding fluid. By modeling a fish as a vortex dipole in an infinite channel with an imposed background flow, we establish a planar dynamical system for the cross-stream coordinate and orientation. The system dynamics captures the existence of a critical flow speed for fish to successfully orient while performing cross-stream, periodic sweeping movements. Model predictions are validated against experimental observations in the literature on the rheotactic behavior of fish deprived of visual and lateral line cues. The crucial role of bidirectional hydrodynamic interactions unveiled by this model points at an overlooked limitation of existing experimental paradigms to study rheotaxis in the laboratory.
\end{abstract}

\section{Introduction}

Swimming animals display a complex behavioral repertoire in response to flows (Chapman et al., 2011). Particularly fascinating is the ability of several fish species to orient and swim against an incoming flow, a behavior known as rheotaxis. While intuition may suggest that vision is necessary for fish to determine the direction of the flow, several experimental studies of midwater species swimming in a channel have documented rheotaxis in the dark above a critical flow speed (Coombs et al., 2020). When deprived of vision, fish lose the ability to hold station and they may perform sweeping, cross-stream movements from one side of the channel to other (Bak-Coleman et al., 2013; Bak-Coleman and Coombs, 2014; Elder and Coombs, 2015) (Fig. 1).

In addition to vision, fish may rely on an array of compensatory sensory modalities to navigate the flow. For example, fish could sense and actively respond to linear accelerations caused by the surrounding flow using their vestibular system (Pavlov and Tjurjukov, 1995). Similarly, with the help of tactile sensors on their body surface, fish could maintain their orientation against a current through momentary contacts with their surroundings (Lyon, 1904; Arnold, 1969). Several modern studies have unveiled the critical role of the lateral line system, an array of mechanosensory receptors located on the surface of fish body (Montgomery and Baker, 2020), in their ability to orient against a current (Montgomery et al., 1997; Baker and Montgomery, 1999), hinting at a hydrodynamics-based rheotactic mechanism that has not been fully elucidated. When deprived 
of vision, can fish rely only on lateral line feedback to perform rheotaxis? Is there a possibility for rheotaxis to be achieved through a purely passive hydrodynamic mechanism that does not need any sensing?

Through experiments on zebrafish larvae swimming in a laminar flow in a straight tube, Oteiza et al. (2017) have recently unveiled an elegant hydrodynamic mechanism for fish to actively perform rheotaxis. Utilizing their mechanosensory lateral line, fish can sense the flow along different parts of their body, which is sufficient for them to deduce local velocity gradients in the flow and adjust their movements accordingly. As further elaborated upon by Dabiri (2017), the insight offered by Oteiza et al. (2017) is grounded in the fundamental relationship between vorticity and circulation given by the Kelvin-Stokes' theorem, so that fish movements will be informed by local sampling of the vorticity field. While offering an elegant pathway to explain rheotaxis, the framework of Oteiza et al. (2017) does not include a way for rheotaxis to be performed in the absence of information about the local vorticity field. Several experimental studies have shown that fish can perform rheotaxis even when their lateral line is partially or completed ablated, provided that the flow speed is sufficiently large (Bak-Coleman et al., 2013; Bak-Coleman and Coombs, 2014; Baker and Montgomery, 1999; Elder and Coombs, 2015; Montgomery et al., 1997; Oteiza et al., 2017; Van Trump and McHenry, 2013).

Mathematical modeling efforts seeking to clarify the mechanisms underlying rheotaxis are scant (Oteiza et al., 2017; Burbano-L and Porfiri, 2021; Colvert and Kanso, 2016; Chicoli et al., 2015), despite experiments on rheotaxis dating back more than a century (Lyon, 1904). A common hypothesis of existing mathematical models is that the presence of the fish does not alter the flow physics with respect to the background flow, thereby neglecting interactions between the fish and the walls of the channel. For example, the model by Oteiza et al. (2017) implements a random walk in a virtual flow, matching experimental measurements of the background flow in the absence of the animal through particle image velocimetry. A similar line of approach was pursued by Burbano- $L$ and Porfiri (2021) for the study of multisensory feedback control of adult zebrafish.

Thus, according to these models, the fish acts as a perfectly non-invasive sensor that probes and reacts to the local flow environment without perturbing it. There are countless examples in fluid mechanics that could question the validity of such an approximation, from coupled interactions between a fluid and a solid in vortex-induced vibrations (Williamson and Govardhan, 2004) to laminar boundary layer response to environmental disturbances that range from simple decay of the perturbation to bypass transition (Saric et alo, 2002). We expect that accounting for bidirectional coupling between the fluid flow and the fish will help clarify many of the puzzling aspects of rheotaxis.

To shed light on the physics of rheotaxis, we formulate a mathematical model based on the paradigm of the finite-dipole, originally proposed by Tchieu et al. (2012a). Within this paradigm, a fish is viewed as a pair of point vortices of equal and opposite strength separated by a constant distance in a two-dimensional plane. The application of the finite-dipole has bestowed important theoretical advancements in the study of hydrodynamic interactions between swimming animals (Gazzola et al., 2016; Filella et al., 2018; Kanso and Tsang, 2014; Kanso and Michelin, 2019), upon which we investigate the bidirectional coupling between a fish and the surrounding fluid flow in a channel. Our work contributes to the recent literature on minimal models of fish swimming (Gazzola et al., 2014, 2015; Sánchez-Rodríguez et al., 2020) that builds on seminal work by Lighthill (1975), Taylor (1952), and Wu (1971) to elucidate the fundamental physical underpinnings of locomotion and inform the design of engineering systems.

We focus on an ideal condition, where fish are deprived of vision, vestibular system, and tactile sensors. Their only potential ability to probe the environment is through their lateral line that gives them access to information about the flow. Such flow information is coupled, however, to the motion of the fish itself, which acts as an invasive sensor and perturbs the background flow. Just as fish motion influences the local flow field, so too does the local flow field alter fish motion through advection. Predictions from the proposed model are compared against existing empirical 


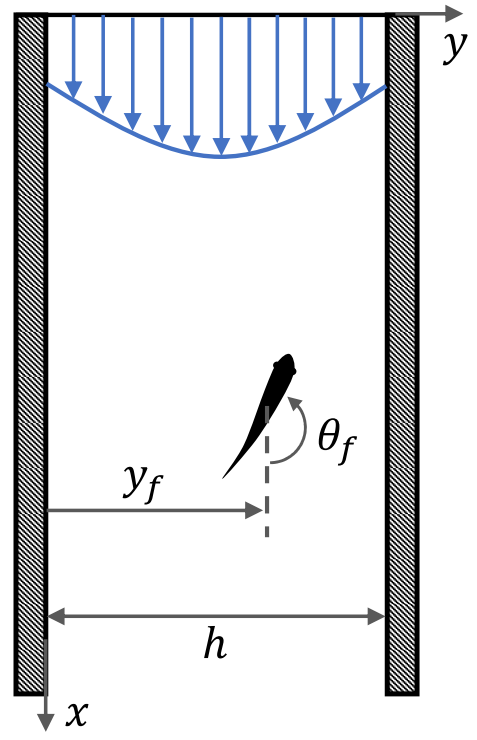

(a)

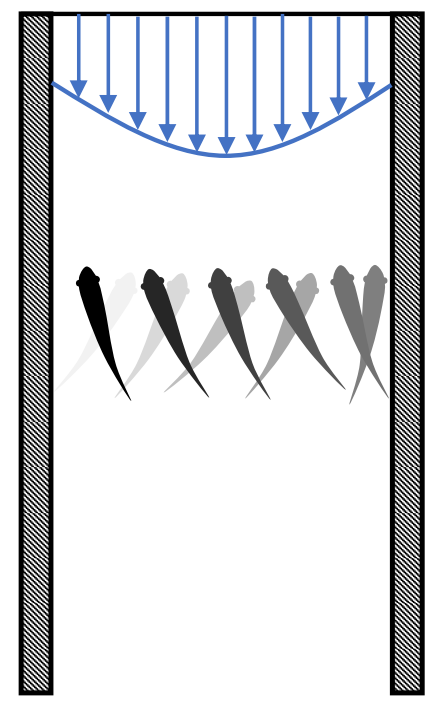

(b)

Figure 1. Fish rheotaxis. (a) Illustration of the problem with notation, showing a fish swimming in a backgroud flow described by Eq. (4). (b) Schematic of the cross-stream sweeping movement of some fish species swimming without visual cues; snapshots of fish at earlier time instants are illustrated by lighter shading.

observations on fish rheotaxis, compiled through a comprehensive literature review of published work since 1900. Data presented in the literature are used to validate the predicted dependence of rheotaxis performance on local flow characteristics, individual fish traits, and lateral line feedback.

\section{Results}

\section{Model of the fluid flow}

Consider a single fish swimming in an infinitely long two-dimensional channel of width $h$ (Fig. 1(a)). Let one wall of the channel be at $y=0$ and the other at $y=h$, with $x$ pointing along the channel. The fish position at time $t$ is given by $\vec{r}_{f}(t)=x_{f}(t) \hat{i}+y_{f}(t) \hat{j}$, where $\hat{i}$ and $\hat{j}$ are the unit vectors in the $x$ and $y$ directions, respectively. The orientation of the fish with respect to the $x$ axis is given by $\theta_{f}(t)$ (positive counter-clockwise) and its self-propulsion velocity is $\vec{v}_{f}=v_{0}\left(\cos \theta_{f} \hat{i}+\sin \theta_{f} \hat{j}\right)=v_{0} \hat{v}_{f}$, where $v_{0}$ is the constant speed of the fish and $\hat{v}_{f}$ is a unit vector in the swimming direction.

The flow is modeled as a potential flow, which is a close approximation of the realistic flow field around a fish. This simple linear fluid model is intended to capture the mean flow physics, thereby averaging any turbulence contribution. The fish is modeled as a finite-dipole (Tchieu et al., 2012a), the potential field of which at some location $\vec{r}=x \hat{i}+y \hat{j}$ is given by

$$
\phi_{f}\left(\vec{r}, \vec{r}_{f}, \theta_{f}\right)=-r_{0}^{2}\left(\frac{\left(\vec{r}-\vec{r}_{f}\right) \cdot \vec{v}_{f}}{\left\|\vec{r}-\vec{r}_{f}\right\|^{2}}\right),
$$

where $r_{0}$ is the characteristic dipole length-scale (on the order of the amplitude of the fish tail beating), so that the circulation of each vortex is $2 \pi r_{0} v_{0}$. This potential field is constructed assuming a far-field view of the dipole (Filella et al., 2018), wherein $r_{0}$ is small in comparison with the characteristic flow length scale, which is satisfied for $\rho=r_{0} / h \ll 1$. The velocity field at $\vec{r}$ due to the dipole (fish) is $\vec{u}_{f}=\nabla \phi_{f}$.

A major contribution of the proposed model is the treatment of the fish as an invasive sensor that both reacts to and influences the background flow, thereby establishing a coupled interaction between the fish and the surrounding environment. A fish swimming in the vicinity of a wall will induce rotational flow near the boundary. In the inviscid limit, this boundary layer is infinitesimally 


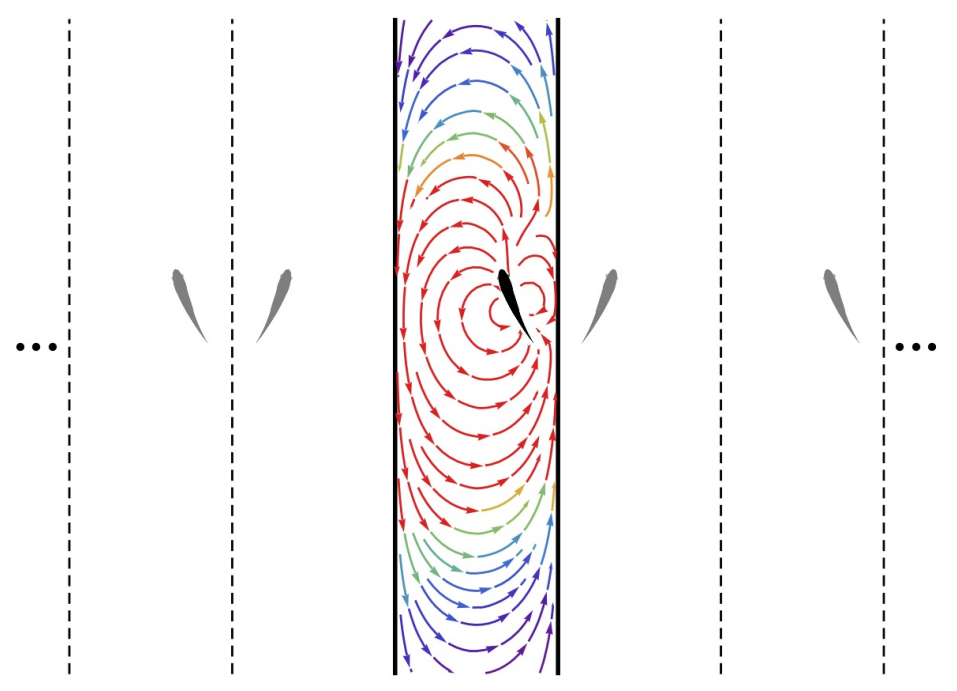

Figure 2. Method of images. Schematic of the fish (black) in the channel (thick lines) and the set of images (gray) needed to generate the channel. The streamlines generated by the fish in an otherwise quiescent fluid are shown in the channel colored by local velocity magnitude (red: high; blue: low). Dashed and solid lines are mirroring planes for the method of images, the pattern for which continues ad infinitum.

122

123

124

125

thin and can be considered as wall-bounded vorticity (Batchelor, 2000). Employing the classical method of images (Newton, 2011), the influence of the wall-bounded vorticity on the flow field is equivalent to that of a fictitious fish (dipole) mirrored about the wall plane. For the case of a fish in a channel, this results in an infinite number of image fish (dipoles) (Fig. 2), the position vectors for which are

$$
\vec{r}_{<, n}^{+}=x_{f} \hat{i}+\left(y_{f}-2(n+1) h\right) \hat{j},
$$

$$
\vec{r}_{<, n}^{-}=x_{f} \hat{i}+\left(-y_{f}-2 n h\right) \hat{j},
$$

$$
\vec{r}_{>, n}^{+}=x_{f} \hat{i}+\left(y_{f}+2(n+1) h\right) \hat{j},
$$

$$
\vec{r}_{>, n}^{-}=x_{f} \hat{i}+\left(-y_{f}+2(n+1) h\right) \hat{j},
$$

where $n$ is a non-negative integer representing the $n$-th set of images. Subscripts " $<$ " and " $>$ " correspond to position vectors of the images at $y<0$ and $y>h$, respectively. Likewise, superscript " \pm " denotes the orientation of the image dipole as $\pm \theta_{f}$; that is, a position vector with superscript " + " indicates that the associated image has the same orientation as the fish.

The potential function for a given image is found by replacing $\vec{r}_{f}$ in (1) with its position vector from (2) and adjusting the sign of $\theta_{f}$ in (1) to match the superscript of its vector. The potential field at $\vec{r}$ due to the image dipoles is

$$
\phi_{w}\left(\vec{r}, \vec{r}_{f}, \theta_{f}\right)=\sum_{n=0}^{\infty}\left(\phi_{f}\left(\vec{r}, \vec{r}_{<, n}^{+}, \theta_{f}\right)+\phi_{f}\left(\vec{r}, \vec{r}_{<, n}^{-},-\theta_{f}\right)+\phi_{f}\left(\vec{r}, \vec{r}_{>, n}^{+}, \theta_{f}\right)+\phi_{f}\left(\vec{r}, \vec{r}_{>, n}^{-},-\theta_{f}\right)\right) .
$$

Thus, the velocity field due to the wall is computed as $\vec{u}_{w}=\nabla \phi_{w}$, and the overall velocity field induced by the fish is $\vec{u}_{f}+\vec{u}_{w}$. (A closed-form expression for the series in terms of trigonometric and hyperbolic functions is presented in Appendix 1.) Overall, the presence of the walls distorts the flow generated by the dipole, both compressing the streamlines between the fish and the walls in its proximity and creating long-range swirling patterns in the channel (Fig. 2). 
153

The presence of a background flow in the channel is modelled by superimposing a weakly rotational flow,

$$
\vec{u}_{b}(\vec{r})=U_{0}\left(1-4 \epsilon\left(\frac{y}{h}-\frac{1}{2}\right)^{2}\right) \hat{i}
$$

which has speed $U_{0}$ at the channel centerline and $U_{0}(1-\epsilon)$ at the walls, $\epsilon$ being a small positive parameter. As $\epsilon \rightarrow 0$, a uniform (irrotational) background flow is recovered: such a flow is indistinguishable from the one in Fig. 2, provided that the observer is moving with the background flow. The overall fluid flow in the channel is ultimately computed as $\vec{u}=\vec{u}_{f}+\vec{u}_{w}+\vec{u}_{b}$.

The circulation in a region $\mathcal{R}$ in the flow field centered at some location $y$ is $\Gamma=\int_{\mathcal{R}} \omega \mathrm{d} A$, where $\omega=(\nabla \times \vec{u}) \cdot \hat{k}$ is the local fluid vorticity $(\hat{k}=\hat{i} \times \hat{j})$. For the considered flow field, we determine

$$
\omega(\vec{r})=\frac{8 U_{0} \epsilon}{h}\left(\frac{y}{h}-\frac{1}{2}\right),
$$

whereby the irrotational component of the flow field does not contribute to the circulation, and the circulation at a point (per unit area) is equivalent to the local vorticity.

\section{Model of fish dynamics}

From knowledge of the fluid flow in the channel, we compute the advective velocity $\vec{U}\left(\vec{r}_{f}, \theta_{f}\right)$ and hydrodynamic turn rate $\Omega\left(\vec{r}_{f}, \theta_{f}\right)$ at the fish location, which encode the influence of the confining walls and background flow on the translational and rotational motion of the fish, respectively. Neglecting the inertia of the fish so that it instantaneously responds to changes in the fluid flow, we determine (Filella et al., 2018)

$$
\dot{\vec{r}}_{f}(t)=\vec{U}\left(\vec{r}_{f}(t), \theta_{f}(t)\right)+\vec{v}_{f}\left(\theta_{f}(t)\right)
$$

$$
\dot{\theta}_{f}(t)=\Omega\left(\vec{r}_{f}(t), \theta_{f}(t)\right)+\lambda\left(\vec{r}_{f}(t), \theta_{f}(t)\right),
$$

where $\lambda$ is the feedback mechanism based on the circulation measurement through the lateral line.

The advective velocity is found by de-singularizing the total velocity field $\vec{u}$ at $\vec{r}=\vec{r}_{f}$, which is equivalent to calculating the sum of the velocity due to the walls and the background flow in correspondence of the fish (Milne-Thomson, 1996)

$$
\begin{aligned}
\vec{U}\left(\vec{r}_{f}, \theta_{f}\right)=\left.\left(\vec{u}_{w}\left(\vec{r}, \vec{r}_{f}, \theta_{f}\right)+\vec{u}_{b}(\vec{r})\right)\right|_{\vec{r}=\vec{r}_{f}} & \\
=-\frac{\pi^{2} v_{0} \rho^{2}}{12}\left[\left(1+3 \csc ^{2}\left(\frac{\pi y_{f}}{h}\right)\right) \cos \theta_{f} \hat{i}-\left(1-3 \csc ^{2}\left(\frac{\pi y_{f}}{h}\right)\right) \sin \theta_{f} \hat{j}\right] & +U_{0}\left(1-4 \epsilon\left(\frac{y_{f}}{h}-\frac{1}{2}\right)^{2}\right) \hat{i} .
\end{aligned}
$$

Equation (7) indicates that the walls have a retarding effect on the swimming speed of the fish that increases in magnitude the closer the fish gets to either wall of the channel. A fish swimming with orientation $\theta_{f}=0$ at the center of the channel, for example, will swim with velocity $\dot{\vec{r}}_{f}(t)=v_{0}(1-$ $\left.\left(\pi^{2} / 3\right) \rho^{2}\right) \hat{i}+U_{0} \hat{i}$. This effect should not be mistaken as traditional viscous drag, which is not included in potential flow theory; rather, it should be intended as the impact of nearby solid boundaries.

Hydrodynamic turn rate is incorporated by considering the difference in velocity experienced by the two constituent vortices comprising the dipole (Filella et al., 2018), namely,

$$
\begin{aligned}
\Omega\left(\vec{r}_{f}, \theta_{f}\right)=-\hat{v}_{f} \cdot\left[\left.\nabla\left(\vec{u}_{w}\left(\vec{r}, \vec{r}_{f}, \theta_{f}\right)+\vec{u}_{b}(\vec{r})\right)\right|_{\vec{r}=\vec{r}_{f}}\right] \hat{v}_{f}^{\perp} \\
=-\frac{\pi^{3} \rho^{2} v_{0}}{4 h} \cot \left(\frac{\pi y_{f}}{h}\right) \csc ^{2}\left(\frac{\pi y_{f}}{h}\right) \cos \theta_{f}+\frac{8 U_{0} \epsilon}{h}\left(\frac{y_{f}}{h}-\frac{1}{2}\right) \cos ^{2} \theta_{f},
\end{aligned}
$$

where $\hat{v}_{f}^{\perp}=\hat{k} \times \hat{v}_{f}$; see Methods and Materials Section for the mathematical derivation. Equation (8) indicates that interaction with the walls causes the fish to turn towards the nearest wall; 
for example, a fish at $y_{f}=3 / 4 h$, will experience a turn rate due to the wall of $\left(\pi^{3} \rho^{2} v_{0}\right) /(2 h) \cos \theta_{f}$, such that it will be rotated counter-clockwise if swimming downstream and clockwise if swimming upstream. On the other hand, the turning direction imposed by the background flow is always positive (counter-clockwise) in the right half of the channel and negative (clockwise) in the left half, irrespective of fish orientation, so that a fish at $y_{f}=3 / 4 h$ will always be rotated counter-clockwise. As a result, the fish may turn towards or away from a wall, depending on model parameters and orientation.

Based on experimental observations and theoretical insight (Burbano-L and Porfiri, 2021; Oteiza et al., 2017), we hypothesize that hydrodynamic feedback, that is, lateral line measurements of the surrounding fluid that fish can employ to navigate the flow, is related to the measurement of the circulation in a region surrounding the fish. We consider a rectangular region $\mathcal{R}$ of width $r_{0}$ along the fish body length $l$. For simplicity, we assume a linear feedback mechanism, $\lambda\left(\vec{r}_{f}, \theta_{f}\right)=K \Gamma\left(\vec{r}_{f}, \theta_{f}\right)$, where we made evident that circulation is computed about the fish location and $K$ is a non-negative feedback gain. Assuming that the fish size is smaller than the characteristic length scale of the flow, we linearize the vorticity along the fish in (5) as $\omega(\vec{r}) \approx \omega\left(\vec{r}_{f}\right)+\nabla \omega\left(\vec{r}_{f}\right) \cdot \hat{v}_{f} \Delta l$. By computing the integral from $\Delta l=-l / 2$ to $l / 2$, we obtain

$$
\lambda\left(\vec{r}_{f}, \theta_{f}\right)=K r_{0} l \frac{8 U_{0} \epsilon}{h}\left(\frac{y_{f}}{h}-\frac{1}{2}\right) .
$$

Compared to established practice for modeling fish behavior in response to visual stimuli (Gautrais et al., 2009; Calovi et al., 2014; Zienkiewicz et al., 2015b; Couzin et al., 2005), the proposed model introduces rich nonlinear dynamics arising from the bidirectional coupling between the motion of the fish and the flow physics in its surroundings. We note that the employed feedback in (9) neglects additional potential sensing mechanisms, including vision (Lyon, 1904), acceleration sensing through the vestibular system (Pavlov and Tjurjukov, 1995), and pressure sensing through sensory afferents in the fins (Hardy et al., 2016), which might enhance the ability of fish to navigate the flow.

\section{Analysis of the planar dynamical system}

Given that the right hand side of equation set (6) is independent of the streamwise position of the fish, the equations for the cross-streamwise motion and the swimming direction can be separately studied, leading to an elegant nonlinear planar dynamical system. We center the cross-stream coordinate about the center of the channel and non-dimensionalize it with respect to $h$, introducing $\xi=y_{f} / h-1 / 2$. The governing equations become

$$
\dot{\xi}=\left[1-\frac{\pi^{2} \rho^{2}}{12}\left(3 \csc ^{2}\left(\pi\left(\xi+\frac{1}{2}\right)\right)-1\right)\right] \sin \theta_{f},
$$

$$
\dot{\theta}_{f}=-\frac{\pi^{3} \rho^{2}}{4} \cot \left(\pi\left(\xi+\frac{1}{2}\right)\right) \csc ^{2}\left(\pi\left(\xi+\frac{1}{2}\right)\right) \cos \theta_{f}+8 \alpha \xi\left(\cos ^{2} \theta_{f}+\kappa\right),
$$

where we non-dimensionalized by the time needed for the fish to traverse the channel in the absence of a background flow, that is, $h / v_{0}$, and introduced $\alpha=U_{0} \epsilon / v_{0}$ and $\kappa=K r_{0} l$ (see Methods and Materials Section for estimation of these parameters from experimental observations).

In search of the equilibria of the dynamical system, we note that swimming downstream or upstream ( $\theta_{f}=0$ and $\pi$, respectively) solves (10a) for any choice of the cross-stream coordinate, the value of which is determined from the solution of $(10 \mathrm{~b})$ for the corresponding orientation $\theta_{f}$. In the case of downstream swimming, the only solution of the resulting transcendental equation is $\xi=0$. For upstream swimming, depending on the value of the parameter $\beta=(\alpha(1+\kappa)) / \rho^{2}$, we have one or three solutions: if $\beta<\beta^{*}=\pi^{4} / 32$, the only solution is $\xi=0$, otherwise, in addition to $\xi=0$, there are two solutions symmetrically located with respect to the centerline that approach the walls as $\beta \rightarrow \infty$ (Fig. 3(a), see Methods and Materials Section for mathematical derivations).

Local stability of these equilibria is determined by studying the eigenvalues of the state matrix of the corresponding linearized dynamics. For all the considered dynamics, the trace of the state 
bioRxiv preprint doi: https://doi.org/10.1101/2021.11.11.468193; this version posted November 12, 2021. The copyright holder for this preprint (which was not certified by peer review) is the author/funder, who has granted bioRxiv a license to display the preprint in perpetuity. It is made available under aCC-BY 4.0 International license.

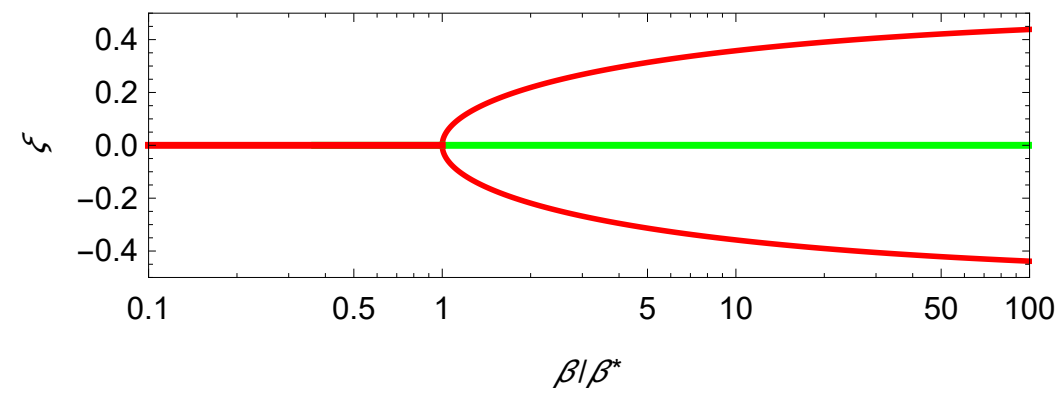

(a)

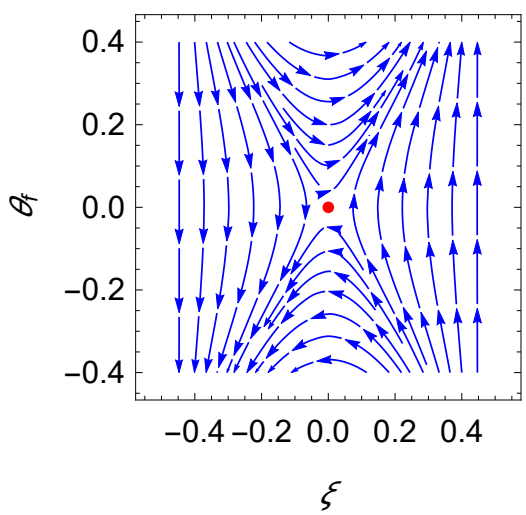

(b)

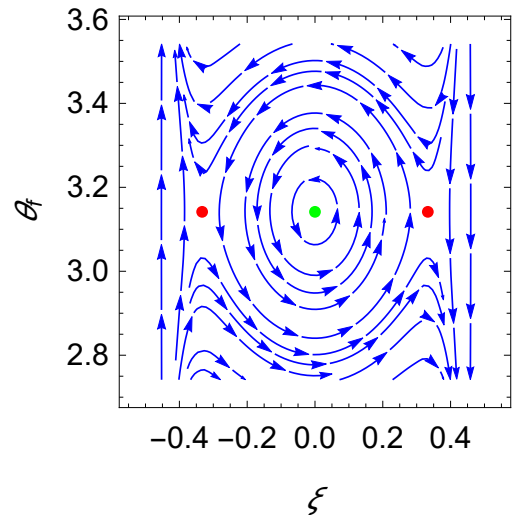

(c)

Figure 3. Qualitative dynamics of equation set (10). (a) Cross-stream equilibria for upstream swimming as a function of $\beta$. (b,c) Phase plot for downstream and upstream swimming in the case $\alpha=0.1, \rho=0.01$, and $\kappa=1$, so that $\beta=20$. In all panels, red refers to unstable equilibria and green to stable equilibria. 
matrix is zero, so that the equilibria can be saddle points (unstable) or neutral centers (stable), if the determinant is negative or positive, respectively (Bakker, 1991) (see Methods and Materials Section for mathematical derivations). In the case of downstream swimming, the determinant is always negative, such that the equilibrium $\left(\theta_{f}=0, \xi=0\right)$ is a saddle point (Fig. 3(b)). For upstream swimming, the equilibrium $\left(\theta_{f}=\pi, \xi=0\right)$ is stable if $\beta>\beta^{*}$, leading to periodic oscillations similar to experimental observations (Bak-Coleman et al., 2013; Bak-Coleman and Coombs, 2014; Elder and Coombs, 2015) (Fig. 1(b)); the other two equilibria located away from the centerline are always unstable (Figs. $3(b, c)$ ). Oscillations about the centerline during rheotaxis have a radian frequency $\omega_{0} \simeq\left(\pi^{2} / 2\right) \rho \sqrt{\beta / \beta^{*}-1}$, such that the frequency increases with the square root of $\beta$ and is zero at $\beta^{*}$ (see Methods and Materials Section for the mathematical derivation).

\section{Validation against empirical observations}

To support our proposed model with existing experimental data, we conducted an expansive literature review, identifying 11 relevant publications after applying a set of inclusion and exclusion criteria (see Methods and Materials Section). In particular, we only included experiments wherein fish performed rheotaxis in the absence of visual cues, in alignment with the assumption of a purely hydrodynamic feedback mechanism in (9).

The studies identified from the literature review are utilized to validate the proposed theoretical framework with respect to the rheotaxis stability threshold. We first express the stability threshold $\beta=\beta^{*}$ in dimensional form in terms of the rheotaxis threshold speed

$$
U_{c}=\frac{\pi^{4} r_{0}^{2} v_{0}}{32 h^{2}\left(1+K r_{0} l\right) \epsilon},
$$

such that $U_{0}>U_{c}$ corresponds to the stable condition $\beta>\beta^{*}$, and vice versa. From most studies, the values of $U_{c}$ can be identified and its confidence level can be inferred (see Methods and Materials Section).

As evidenced in (11), a series of parameters could influence the rheotaxis threshold speed, including the lateral line feedback, flow gradient, swimming domain size, and fish body length. Specifically, (11) predicts that increasing the lateral line feedback, flow gradient, and/or width of swimming channel promotes rheotaxis at lower flow speeds, whereas increasing fish size will require higher flow speeds to elicit rheotactic behavior. The effects of these parameters are validated independently in Table 1, where we include experimental evidence garnered within each study and, when possible, carry out a comparison, across them. We compare each of these empirical observations to model predictions, and assess if they support the model, contradict the model, or are inconclusive. An observation is considered supportive of (contradictive to) our model if the measured $U_{c}$ exhibits with statistical significance the same (opposite) dependence on a certain parameter (see Methods and Materials Section for details on the statistical analysis). Data that lack statistical significance are considered inconclusive.

Several studies provide evidence in favor of the prediction of our model of the beneficial role of lateral line feedback, showing a significant reduction in rheotactic performance when the lateral line is compromised (Kulpa et al., 2015; Oteiza et al., 2017; Suli et al., 2012), see Table 1. In these studies, fish locomotion was measured in steady background flows, so that a fish holding station would experience minimal linear acceleration and marginally engage the vestibular system. Throughout these studies, fish were not observed to make contact with the swim channel, indicating that tactile senses played a negligible role in rheotaxis.

We identified two studies (Lyon, 1904; Oteiza et al., 2017) that could validate the predicted effect of the flow velocity gradient on rheotaxis, as summarized in Table 1. In both studies, fish locomotion was recorded in flows with varying velocity gradients. In agreement with the proposed model, the rheotaxis performance of zebrafish larvae significantly improved with increasing gradient magnitudes (Oteiza et al., 2017). Similar observations were obtained by Lyon on blind Fundulus (Lyon, 1904), where in a flow with a small gradient, fish performed rheotaxis only when tactile cues were 
available, while in a jet flow with a large flow gradient, rheotaxis could be elicited solely by the flow. Although qualitatively in line with our predictions, we conservatively considered this study as inconclusive due to a lack of quantitative data for statistical tests.

To elucidate the role of the swimming domain size on rheotaxis threshold speed, we conducted cross-study comparisons as shown in Table 1. As evidenced through comparisons between two experiments on zebrafish larvae (Oteiza et al., 2017; Peimani et al., 2017) in swim channels of drastically different sizes, rheotaxis was elicited at a higher threshold speed in a smaller flow channel, which supports our model prediction. Our model is also qualitatively supported by comparisons between Bak-Coleman and Coombs (2014) and Baker and Montgomery (1999), or Bak-Coleman and Coombs (2014) and Van Trump and McHenry (2013), where experiments on blind cavefish of comparable body sizes uncovered higher threshold speeds in smaller flow channels. In the experiments of Bak-Coleman and Coombs (2014), blind cavefish were observed to receive transient tactile senses while swimming, which could have contributed to its lower rheotaxis threshold. As a result, experimental data on blind cavefish were conservatively deemed to be inconclusive.

To validate the effect of fish body size on the rheotaxis threshold speed, we examined a pair of studies by Bak-Coleman and Coombs (2014) and Elder and Coombs (2015), where experiments were conducted on fish of the same species (Astyanax mexicanus) in swim tunnels of the same size, and tested in flows at a similar range of speeds. The high flow speeds in both studies suggest that the flow gradients in these experiments were small. We assume that the lateral line feedback were equivalent in both studies, as the subjects were conspecific. Although the tactile cues present in the experiments by Bak-Coleman and Coombs (2014) hinder our ability to reach a definitive conclusion on the effect of fish body size, the higher threshold speed observed in larger fish qualitatively supports our model prediction (see Methods and Materials Section). The paucity of data for validation of the effect of fish size is a result of a lack of studies with matching experimental conditions, including dimensions of the flow facilities, flow conditions, and functionality of the lateral line.

In summary, we identified a total of five sets of experiments in support of our model, and nine sets of studies that offer inconclusive evidence. None of the data contradicted predictions from the proposed model.

Table 1. Results of the bibliographical research on fish rheotaxis in the absence of visual cues, used to validate the proposed model.

\begin{tabular}{|c|c|c|c|c|}
\hline \multirow{2}{*}{ Reference } & \multirow{2}{*}{ Fish species } & \multirow{2}{*}{${ }^{\dagger}$ Evidence } & \multicolumn{2}{|c|}{ Comparison with model } \\
\hline & & & Supportive & Inconclusive \\
\hline \multicolumn{5}{|l|}{$\begin{array}{l}\text { Within studies } \\
\text { Effect of lateral line }\end{array}$} \\
\hline $\begin{array}{l}\text { Bak-Coleman } \\
\text { et al. (2013) }\end{array}$ & $\begin{array}{l}\text { Giant danio (Devario } \\
\text { aequipinnatus) }\end{array}$ & $\begin{array}{l}\text { No significant difference in fish heading } \\
\text { angle against current was detected } \\
\text { between LL+ and LL- }\end{array}$ & & $x$ \\
\hline Bak-Coleman & blind cavefish & Rheotaxis threshold speed was slightly (but & & $x$ \\
\hline $\begin{array}{l}\text { and Coombs } \\
(2014)\end{array}$ & (Astyanax mexicanus) & not significantly) lower in LL- condition & & \\
\hline Baker & blind cavefish & Rheotaxis threshold speed was significantly & & $x$ \\
\hline $\begin{array}{l}\text { Montgomery } \\
(1999) \quad \text { and }\end{array}$ & (Astyanax fasciatus) & $\begin{array}{l}\text { higher in LL- condition; fish received } \\
\text { intermittent tactile senses }\end{array}$ & & \\
\hline \multicolumn{5}{|l|}{$\begin{array}{l}\text { Montgomery } \\
\text { et al. (1997) }\end{array}$} \\
\hline $\begin{array}{l}\text { Elder and } \\
\text { Coombs (2015) }\end{array}$ & $\begin{array}{l}\text { Mexican tetras } \\
\text { (Astyanax mexicanus) }\end{array}$ & $\begin{array}{l}\text { No significant influence of LL condition was } \\
\text { detected on rheotactic performance }\end{array}$ & & $x$ \\
\hline $\begin{array}{l}\text { Kulpa et al. } \\
(2015)\end{array}$ & $\begin{array}{l}\text { blind cavefish } \\
\text { (Astyanax mexicanus) }\end{array}$ & $\begin{array}{l}\text { Significantly higher rheotaxis index in LL+ } \\
\text { fish than LL- fish in jet stream }\end{array}$ & $x$ & \\
\hline $\begin{array}{l}\text { Oteiza et al. } \\
(2017)\end{array}$ & $\begin{array}{l}\text { zebrafish (Danio } \\
\text { rerio) larva } 5-7 \mathrm{dpf}\end{array}$ & $\begin{array}{l}\text { Posterior lateral line ablation or chemical } \\
\text { neuromast ablation severely reduced } \\
\text { rheotaxis }\end{array}$ & $x$ & \\
\hline Suli et al. (2012) & $\begin{array}{l}\text { zebrafish (Danio } \\
\text { rerio) larva } 5 \mathrm{dpf}\end{array}$ & $\begin{array}{l}\text { LL hair cell damage led to a significant } \\
\text { decrease in rheotaxis; regeneration of LL } \\
\text { hair cells restored rheotaxis }\end{array}$ & $x$ & \\
\hline
\end{tabular}


bioRxiv preprint doi: https://doi.org/10.1101/2021.11.11.468193; this version posted November 12,2021 . The copyright holder for this preprint (which was not certified by peer review) is the author/funder, who has granted bioRxiv a license to display the preprint in perpetuity. It is made available under aCC-BY 4.0 International license.

Table 1. Results of the bibliographical research on fish rheotaxis in the absence of visual cues, used to validate the proposed model.

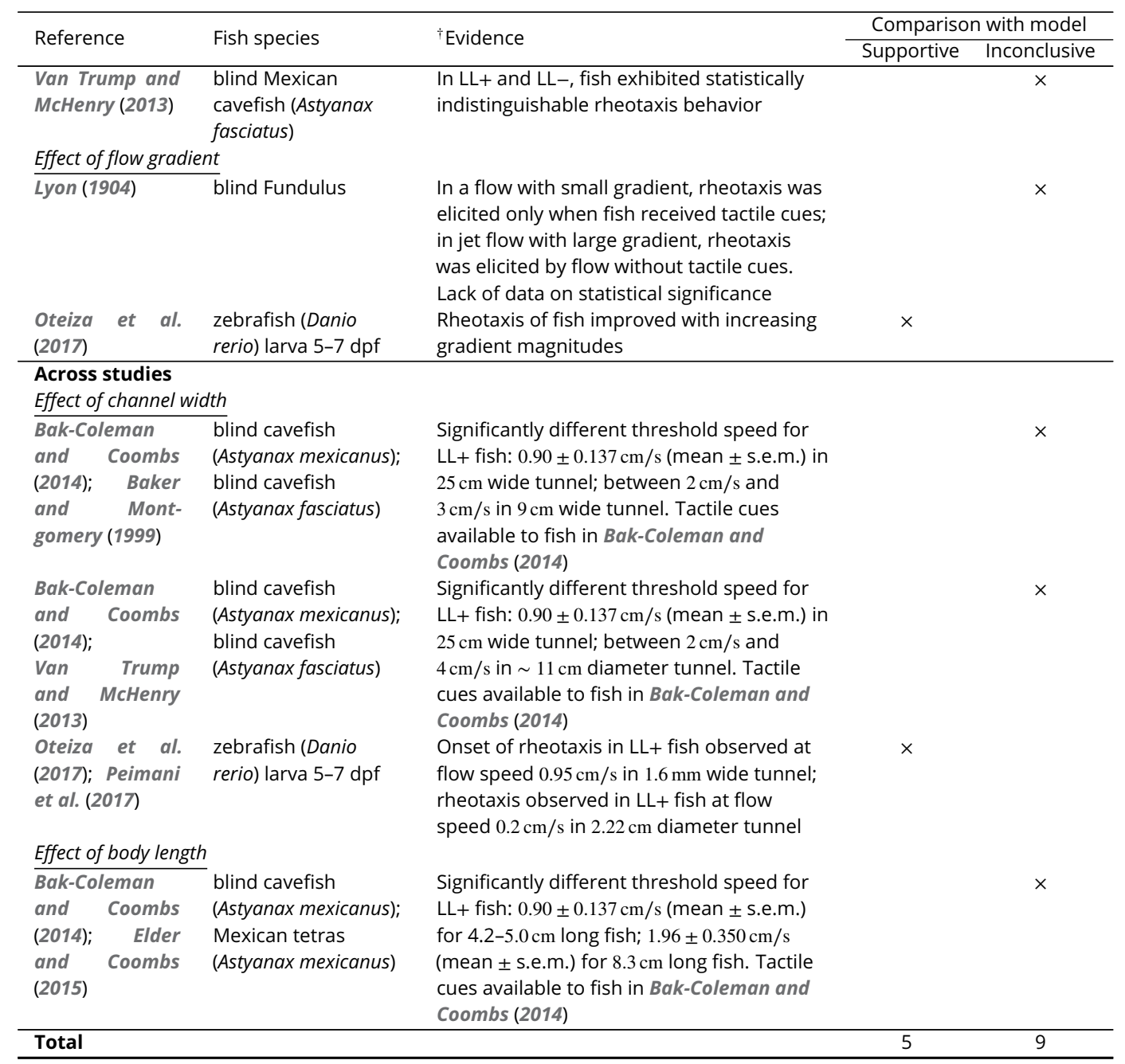

\section{Discussion} There is overwhelming evidence that fish can negotiate complex flow environments by responding to even small flow perturbations (Liao, 2007). However, seldom are these perturbations included in mathematical models of fish behavior, which largely rely on vision cues (Gautrais et al., 2009; Calovi et al., 2014; Zienkiewicz et al., 2015b; Couzin et al., 2005). In this paper, we proposed a hydrodynamic model for the bidirectional coupling between fish swimming and fluid flow in the absence of any sensory input but lateral line feedback. The model reduces to a nonlinear planar dynamical system for the cross-stream coordinate and orientation, of the kind that are featured in nonlinear dynamics textbooks for their elegance, analytical tractability, and broad physical interest (Sastry, 2013).

The planar system anticipates several of the surprising features that have challenged our understanding of rheotaxis for over a century. In agreement with experimental observations on fish swimming in the absence of visual cues (see Table 1), we uncovered an equilibrium at the channel centerline for upstream swimming whose stability is controlled by a single non-dimensional parameter that summarizes flow speed, flow gradient, lateral line feedback, fish size, and channel width. Above a critical value of this parameter, the model predicts that rheotaxis is stable and 
fish will begin periodic cross-stream sweeping movements whose amplitude can be as large as the channel width.

The mathematical proof of the existence of a nontrivial threshold for $\beta$ above which upstream swimming in the absence of visual cues becomes stable is in agreement with experimental observations on a number of species (see Table 2). Experiments have indicated the existence of a threshold in the flow speed or flow gradient above which fish successfully perform rheotaxis, in the absence of visual stimuli. Importantly, the presence of the walls is necessary for the emergence of such a threshold, since for $\rho \rightarrow 0, \beta \rightarrow \infty$, thereby automatically guaranteeing the stability of upstream swimming, against experimental evidence. Based on our estimation of $\alpha$ and $\rho, \beta$ can be as small as $10^{-1}$ and exceed $10^{2}$, thereby encompassing the critical value $\beta^{*} \simeq 3$ (see Methods and Materials Section for estimation of model parameters).

The determination of such a threshold resolves a long-standing dilemma about the role of hydrodynamics on rheotaxis, laid bare by Lyon (1904) in 1904: "It is equally absurd to imagine a fish in the Gulf Stream to be stimulated and oriented by a uniform forward motion of the water. Whether orientation be a simple reflex or a conscious process, points of reference - i.e., points relatively at rest - are necessary." Such points of reference could be visual stimuli (Davidson, 1949), static objects near the bottom of the swimming channel (Needham and Jones, 1959), or hydrodynamic points of reference consisting of flow regions with distinctive features from the background. It is the gradient of the flow that creates hydrodynamic points of reference for a fish to undertake rheotaxis in the dark, even without access to sensory information through the lateral line. The higher is the speed of the flow with respect to the speed of the animal, the more the role of these hydrodynamic reference points will be magnified until reaching the stability threshold for rheotaxis.

The model is successful in predicting the emergence of rheotaxis in the absence of sensory information from the lateral line and visual cues (see Table 1). Setting $\kappa=0$ in our model eliminates hydrodynamic feedback, yet, the fish is able to perform rheotaxis at sufficiently large flow speeds and steep flow gradients. Increasing $\kappa$ broadens the stable region, leading to more robust rheotaxis, in agreement with experimental observations of blind cavefish (Kulpa et al., 2015) and zebrafish larvae (Oteiza et al., 2017; Suli et al., 2012) with intact versus compromised lateral lines (see Table 1).

The model prediction on the influence of the environment, including the flow gradient and flow channel size, on rheotaxis in the absence of visual cues is also supported by observations in the literature. Consistent with observations on zebrafish larvae by Oteiza et al. (2017), increasing the flow gradient $\epsilon$ enhances hydrodynamic feedback, resulting in improved rheotaxis. In contrast to Oteiza et al. (2017), however, the proposed model treats the fish as an invasive sensor, accounting for interactions between the fish and the walls of the channel. The model anticipates that wider channels should promote rheotaxis, which is supported by experimental observations (Baker and Montgomery, 1999; Van Trump and McHenry, 2013; Bak-Coleman and Coombs, 2014; Oteiza et al., 2017; Peimani et al., 2017) (see Table 1). Similarly, in alignment with experimental observations (Bak-Coleman and Coombs, 2014; Elder and Coombs, 2015), the model predicts a lower threshold for longer fish, owing to a magnification of the hydrodynamic feedback received by a longer body.

Finally, the model anticipates the onset of periodic cross-stream sweeping, which has been studied in some experiments on fish swimming in channels without vision (Coombs et al., 2020). While there is not conclusive experimental evidence regarding the dependence of the frequency of oscillations on flow conditions, the model is in qualitative agreement with experiments by Elder and Coombs (2015), showing a sublinear dependence on the flow speed. Therein, it is shown that the radian frequency has a weak positive tendency with respect to the flow speed for Mexican tetra swimming with or without cues from the lateral line. Above $2 \mathrm{~cm} \mathrm{~s}^{-1}$, the animals can successfully perform rheotaxis and display sweeping oscillations at about three cycles per minute and increase to about four cycles per minute at $12 \mathrm{~cm} \mathrm{~s}^{-1}$. These correspond to a radian frequency on the order of $0.1 \mathrm{rad} \mathrm{s}^{-1}$, which is similar to what we would predict for $\beta$ ranging from $10^{0}$ to $10^{1}$ and $\rho$ of the order of $10^{-1}$ (recall that the time is scaled with respect to time required by the animal to traverse 
the channel from wall to wall in the absence of a background flow).

Most experiments used in our model validation listed in Table 2 were conducted in the past 25 years, and only two studies date back to before 1970. This disparity is attributed to an evolution of the methodologies for the study of rheotaxis over time. Among the earlier efforts, a large portion relied on observations of fish behavior in the field (Arnold, 1974). Although these studies minimized the introduction of external stimuli stemming from human presence and unfamiliar environments that could alter the behavior of fish in the wild, a lack of flexibility in the design of controlled experiments in the field, together with an insufficient measurement resolution, has led to only a limited number of works that could distinguish the impact of one sensory cue from another. As a result, a large number of earlier efforts do not meet our inclusion criteria (see Methods and Materials Section).

Likely, the interest in fish rheotaxis was recently reignited owning to the advancements in technologies that could selectively deactivate specific fish sensory organs, thereby allowing for the targeted investigation of the role of each sensory cue in rheotaxis. For instance, pharmacological methods that could disable the lateral line led to studies (Montgomery et al., 1997; Baker and Montgomery, 1999) challenging the long-standing perception that the lateral line could not mediate rheotaxis. In addition, the development of high speed cameras with infra-red sensing capabilities enabled precise measurements of fish behavior in the dark, allowing for the elimination of visual cues from the study of lateral line functionality in rheotaxis. Some early experiments that have been considered in the past as evidence against the role of the lateral line are not listed in Table 2 due to a lack of a controlled experimental design in the field setting. For example, some species of salmonids, including salmon and trout, were observed to swim against the current in the day and rest on the bottom of a stream at night (Davidson, 1949; Gibson, 1966; Edmundson et al., 1968), leading to a conclusion that the lateral line played a minimal role in rheotaxis (Arnold, 1974). However, we did not include these experiments for our model validation due to confounding factors posed by the field settings, such as variations in water temperature (Needham and Jones, 1959; Edmundson et al., 1968; Fraser et al., 1993) and current speeds at different hours of the day. Daily fluctuations in the availability of food (Waters, 1962; Elliott, 1965) is another factor that could influence the activity levels of fish at night, as observed in white bass (McNaught and Hasler, 1961) and trout (Elliott, 1965). Another class of experiments that led to the previous rejection of lateral line was the demonstration of the imperative role of vision in rheotaxis. Experiments on salmon (Hoar, 1954) and herring (Brawn, 1960) showed a reduction in rheotaxis when vision was obscured in the dark or in muddy water, conflating the role of visual cues in rheotaxis. Again, these observations do not directly contradict the proposed model, which suggests that in the absence of visual cues, rheotaxis could still manifest provided that the flow speed is sufficiently high.

Just as other minimal models of fish swimming have helped resolve open questions on scaling laws (Gazzola et al., 2014), gait (Gazzola et al., 2015), and drag (Sánchez-Rodríguez et al., 2020), the proposed effort addresses some of the baffling aspects of rheotaxis through a transparent and intuitive treatment of bidirectional hydrodynamic interactions between fish and their surroundings. The crucial role of these bidirectional interactions hints that active manipulation of their surroundings by fish offers them a pathway to overcome sensory deprivation when swimming in the dark or in the absence of feedback from their lateral line.

The proposed model is not free of limitations, which should be addressed in future research. From a theoretical point of view, the current model neglects the elasticity and inertia of the fish, which might reduce the accuracy in the prediction of rheotaxis, especially transient phenomena. Future research should refine the dipole paradigm toward a dynamic model that accounts for added mass effects and distributed elasticity, similar to those used in the study of swimming robots (Sfakiotakis et al., 1999; Colgate and Lynch, 2004). Likewise, the current model does not describe contact and impact with the walls of the channel, which could be important in further detailing the onset of cross-sweeping motions that could involve stick-and-slip at the bottom of the channel (Van Trump and McHenry, 2013). The model could also be expanded to account for additional 
sensory modalities, such as vision, vestibular system, and tactile sensors on the fish body surface; however, any of these extension shall require detailed experiments to tease out the contribution of each of these sensory modalities (Coombs et al., 2020).

Even within the current scope of the model, further experiments could strengthen its predictive value. For example, the model assumes a linear hydrodynamic feedback mechanism, which is yet to be validated experimentally; in this vein, future experiments should be designed to parametrically vary the flow speed and quantify the activity level of lateral line nerve fibers through neurophysiological recordings (Mogdans, 2019). We also see merit in experiments with robotic fish (Zhang et alo, 2016), mimicking the swimming gait of live animals and allowing to precisely control sensory input. In this vein, we foresee experiments with robotic fish in a complete openloop operation that does not utilize any sensory input. These experiments could bring conclusive evidence to our model predictions of a purely passive hydrodynamic pathway to rheotaxis, which can only be partially supported through live experiments where live fish may still have access and utilize the vestibular system and tactile sensors.

Despite its limitations, the proposed minimalistic model is successful in anticipating many of the puzzling aspects of rheotaxis and points at the possibility of attaining rheotaxis in a purely passive manner, without any sensory input. Most importantly, the model brings forward a potential methodological oversight of laboratory practice in the study of rheotaxis, caused by bidirectional hydrodynamic interactions between the swimming fish and the fluid flow. To date, there is no gold standard for the selection of the size of the swimming domain, which is ultimately chosen on the basis of practical considerations, such as facilitating behavioral scoring and creating a laminar background flow. The model demonstrates that the width of the channel has a modulatory effect on the threshold speed for rheotaxis and the cross-stream swimming frequency, which challenges the comparison of different experimental studies and confounds the precise quantification of the role of individual sensory modalities on rheotaxis. Overall, our effort warrants reconsidering the behavioral phenotype of rheotaxis, by viewing fish as an invasive sensor that modifies the encompassing flow and hydrodynamically responds to it.

\section{Methods and Materials}

\section{Derivation of the turn rate equation for the fish dynamics}

The expression for the turning moment in equation (8) is obtained from the original finite-dipole model by Tchieu et al. (2012b), in the limit of small distances between the vortices in the pair $\left(r_{0} \rightarrow 0\right)$.

Specifically, equation (2.11) from Tchieu et al. (2012b), adapted to the case of a single dipole reads

$$
\dot{\theta}_{f}=\operatorname{Re}\left[\frac{\left(\mathcal{V}\left(\vec{r}_{f, r}\right)-i \mathcal{V}\left(\vec{r}_{f, r}\right)\right)-\left(\mathcal{V}\left(\vec{r}_{f, l}\right)-i \mathcal{V}\left(\vec{r}_{f, l}\right)\right)}{r_{0}} e^{i \theta_{f}}\right],
$$

where subscript $l$ and $r$ refer to the left and right vortices forming the pair and $\vec{v}=V \hat{i}+\mathcal{V} \hat{j}$ is the advective velocity field acting on the dipole. The advective field consists of the interactions with the walls and the background flow, so that $\vec{V}(\vec{r})=\vec{u}_{w}\left(\vec{r}, \vec{r}_{f}, \theta_{f}\right)+\vec{u}_{b}(\vec{r})$; in the case of Tchieu et al. (2012b), such a field encompasses the velocity field induced by any other dipole in the plane. Left and right vortices are defined so that $\vec{r}_{f, l}=\vec{r}_{f}+r_{0} \hat{v}_{f}^{\perp} / 2$ and $\vec{r}_{f, r}=\vec{r}_{f}-r_{0} \hat{v}_{f}^{\perp} / 2$, which yields $\vec{r}_{f, l}-\vec{r}_{f, r}=\hat{v}_{f}^{\perp} r_{0}$.

By carrying out the complex algebra in (12), we determine

$$
\dot{\theta}_{f}=\left(\frac{-\vec{V}\left(\vec{r}_{f, l}\right)+\vec{V}\left(\vec{r}_{f, r}\right)}{r_{0}}\right) \cdot \hat{v}_{f},
$$

which supports the intuition that the dipole will turn counter-clockwise if the right vortex would experience a stronger velocity along the swimming direction. Upon linearizing the term in parenthesis in the neighborhood of $\vec{r}_{f}$, this expression becomes

$$
\dot{\theta}_{f}=-\nabla \vec{v}\left(\vec{r}_{f}\right) \hat{v}_{f}^{\perp} \cdot \hat{v}_{f} .
$$




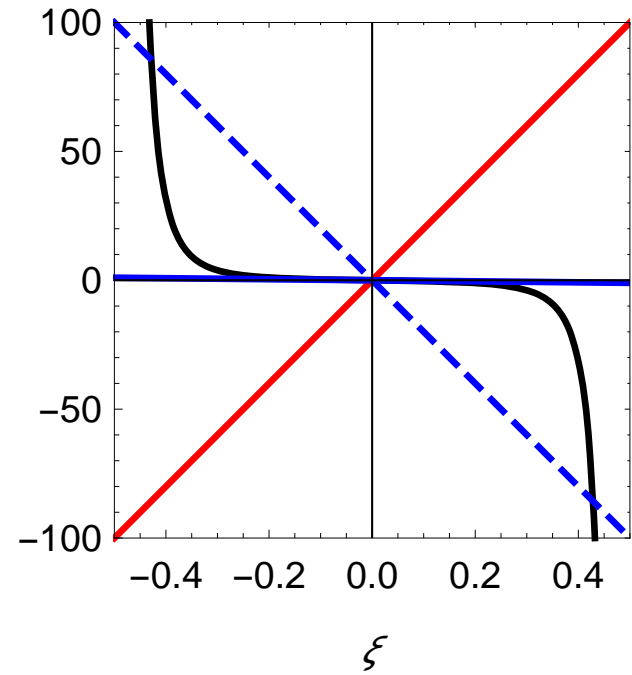

(a)

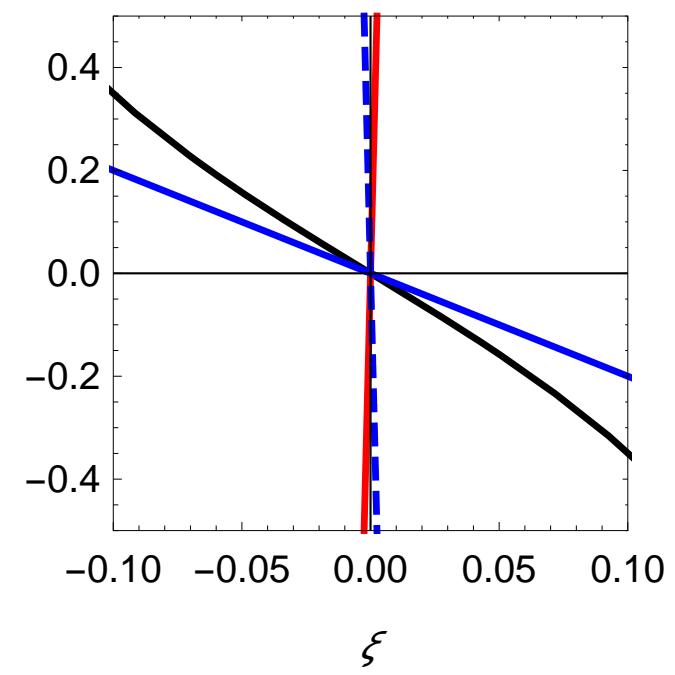

(b)

Figure 4. Visual illustration of the process of determining the roots of (15). (a) Plot of the function $\frac{\pi^{3}}{32} \cot \left(\pi\left(\xi+\frac{1}{2}\right)\right) \csc ^{2}\left(\pi\left(\xi+\frac{1}{2}\right)\right)$ (black), superimposed with three lines of different slope: 200 (red), -200 (dashed blue), and -2 (solid blue). (b) Zoomed-in view of the curves in (a) showing that the blue line can only intersect the black curve at the origin.

\section{Determination of the equilibria of the planar dynamical system}

By setting $\theta_{f}=0$ or $\theta_{f}=\pi$ in equation set (10), we determine that $\xi$ should be equal to some constant, which is a root of the following transcendental equation:

$$
\frac{\pi^{3}}{32} \cot \left(\pi\left(\xi+\frac{1}{2}\right)\right) \csc ^{2}\left(\pi\left(\xi+\frac{1}{2}\right)\right)= \pm \beta \xi
$$

where the positive sign corresponds to $\theta_{f}=0$ and the negative sign to $\theta_{f}=\pi$. Here, $\beta=\alpha(1+\kappa) / \rho^{2}$ as introduced from the main text.

As shown in Fig. 4, for $\theta_{f}=0$, there is only one root of the equation ( $\xi=0$; see the intersection between the solid red line and the solid black curve), while up to three roots can rise for $\theta_{f}=\pi$ depending on the value of $\beta$. For $\beta$ smaller than a critical value $\beta^{*}$, only $\xi=0$ is a solution (see the intersection between the solid blue line and the solid black curve), while for $\beta>\beta^{*}$ two additional solutions, symmetrically located with respect to the origin emerge (see the intersections between the dashed blue line and the solid black curve). The critical value $\beta^{*}$ is identified by matching the slope of the black curve at $\xi=0$, so that $\beta^{*}=\pi^{4} / 32$. Notably, the two solutions symmetrically located with respect to the centerline approach the walls as $\beta \rightarrow \infty$.

\section{Local stability analysis of the planar dynamical system}

To examine the local stability of the equilibria of the planar dynamical system, we linearize equation set (10). The state matrix of the linearized dynamics, $A$, describes the local behavior of the nonlinear system when perturbed in the vicinity of the equilibrium, that is,

$$
\dot{\delta \mathbf{q}}(t)=A \delta \mathbf{q}(t)
$$

where $\delta \mathbf{q}=\left[\delta \xi, \delta \theta_{f}\right]^{\mathrm{T}}$ is the variation about the equilibrium. The eigenvalues of the $A$ are indicative of local stability about each equilibrium.

For $\theta_{f}=0$ and $\xi=0$, the state matrix is given by

$$
A=\left[\begin{array}{cc}
0 & 1-\frac{\pi^{2} \rho^{2}}{6} \\
8(1+\kappa) \alpha+\frac{\pi^{4} \rho^{2}}{4} & 0
\end{array}\right] .
$$


464 Given that the trace of the matrix is zero $(\operatorname{tr} A=0)$, the analysis of the stability of the equilibrium 465 resorts to ensuring the sign of the determinant to be positive $(\operatorname{det} A>0)$. Specifically, if the deter${ }_{466}$ minant is positive, the eigenvalues are imaginary and the equilibrium is a neutral center (stable, ${ }_{467}$ although not asymptotically stable), otherwise one of the eigenvalues is positive and the equilib468 rium is a saddle point (unstable) (Bakker, 1991). Hence, stability requires that

$$
\frac{1}{24}\left(-6+\pi^{2} \rho^{2}\right)\left(32 \alpha(1+\kappa)+\pi^{4} \rho^{2}\right)>0 .
$$

469 Since the first factor is always negative $(\rho \ll 1)$ and the second is positive, the inequality is never 470 fulfilled and the equilibrium is a saddle point (unstable) (Fig. 3(a,b)).

471

For $\theta_{f}=\pi$ and $\xi=0$, the state matrix is given by

$$
A=\left[\begin{array}{cc}
0 & -1+\frac{\pi^{2} \rho^{2}}{6} \\
8(1+\kappa) \alpha-\frac{\pi^{4} \rho^{2}}{4} & 0
\end{array}\right] .
$$

472

Similar to the previous case, stability requires that $\operatorname{det} A>0$, that is,

$$
\frac{1}{24}\left(-6+\pi^{2} \rho^{2}\right)\left(-32 \alpha(1+\kappa)+\pi^{4} \rho^{2}\right)>0 .
$$

473 Due to the sign change in the first summand appearing in the second factor with respect to the

474

475

476

477

478

which is not satisfied for any choice of $\beta>\beta^{*}$. Thus, the two equilibria away from the channel ${ }_{484}$ centerline, close to the walls are always saddle points (unstable) (Figs. $3(a, c)$ ).

\section{Frequency of cross-stream sweeping}

486 The linearized planar system about the stable focus in (19) is equivalent to a classical second-order 487 system in terms of the cross-stream coordinate, similar to a mass-spring model. Hence, the radian 488 resonance frequency of the system is

$$
\omega_{0}=\sqrt{\operatorname{det} A} \simeq \frac{\pi^{2}}{2} \rho \sqrt{\frac{\beta}{\beta^{*}}-1} .
$$

489 where the last approximation holds for $\rho \ll 1$. Equation (24) shows that, close to the threshold, the 490 frequency of oscillations is small and it increases with $\beta$ and $\rho$. 
491

492

493

494

495

496

497

498

499

500

501

502

503

504

\section{Bibliographical survey}

We surveyed over three hundred publications cited by Arnold (1974) and Coombs et al. (2020) - two review papers on rheotaxis, with the former focusing on early investigations from 1900s to 1970s, and the latter highlighting more recent works conducted between 1970s and 2020. Publications were selected through the following inclusion and exclusion criteria.

Inclusion criteria: We select studies where: i) the subject animals were fish; ii) fish demonstrated rheotactic behavior; iii) no unsteady flow events were present in the swimming domain, such as the wake structure of obstacles; iv) the sensory cues available to fish could be identified with some confidence; v) fish behavior was not influenced by social interactions; vi) fish swam without visual cues; and vii) the publication was written in English. Within criterion iii), we focused on experiments with steady flows where the flow gradient is consistent over time, thus excluding swimming in random flow events. Criterion vi) was introduced to direct our search toward the effects of hydrodynamic cues and lateral line sensing, which limited our search to experiments using blind fish or experiments in the dark.

Exclusion criteria: Among studies identified through the selection criteria, we excluded experiments on pleuronectiform flatfishes, which swim on their side and generate propulsive undulations in a vertical plane (Webb, 2002). This locomotory pattern differs fundamentally from the current model, derived on the assumption the fish align their bodies vertically and undulate on a horizontal plane, which is the swimming strategy of the majority of fishes.

Table 2 presents data extracted from the selected studies, including the fish species, size of the swimming domain, flow conditions, sensory cues available to the fish, and the measured rheotaxis threshold speed. Swimming domains with rectangular cross-sections are defined by their length $(L)$, width $(h)$, and depth $(W)$, while swimming domains with circular cross-sections by their length and diameter $(D)$. Flow conditions are quantified through the flow speed and the flow gradient. If information of the flow gradient was not measured in a study, we qualitatively estimated its value through the Reynolds number of the flow, defined based on the width of the channel (or diameter of the channel in case of a cylindrical domain) and the background flow speed as $\operatorname{Re}=\frac{h U_{0}}{v}$ (or $\operatorname{Re}=\frac{D U_{0}}{v}$ ), where $v$ is the kinematic viscosity of water at room temperature. For a sufficiently high $\mathrm{Re}$, the flow gradient near the center of the channel is expected to be low.

When possible, we made direct comparisons between studies, as detailed in Table 1. The confidence intervals of the measured $U_{c}$ values were estimated to determine if $U_{c}$ were significantly different across studies. When the mean and standard error of the mean (s.e.m.) of $U_{c}$ were provided, we estimated its $95 \%$ confidence interval as (mean -1.96 s.e.m., mean +1.96 s.e.m.). If the confidence intervals of two $U_{c}$ values did not overlap, we considered them significantly different. For instance, in Bak-Coleman and Coombs (2014) and Elder and Coombs (2015), the confidence intervals of $U_{c}$ were determined to be $(0.63,1.17) \mathrm{cm} / \mathrm{s}$ and $(1.27,2.64) \mathrm{cm} / \mathrm{s}$, respectively, and thus the $U_{c}$ values were considered significantly different.

In several studies, such as Baker and Montgomery (1999) and Van Trump and McHenry (2013), the threshold speeds were only estimated as intervals, where fish swimming below a lower bound did not perform rheotaxis, while they exhibited rheotaxis above an upper bound. We treated this speed interval as the confidence interval for $U_{c}$ in our statistical analysis.

The relationship between the threshold speed and fish body size is less straightforward, as the body size not only determines the value of $l$, but also influences $r_{0}$, which is on the order of the fish tail beat amplitude. We assumed $r_{0}=0.2 l$, which is a typical tail-beat-amplitude-to-body-length ratio (Gazzola et al., 2014). For fish with functional lateral lines that produce positive feedback, $K>0$, we obtain $U_{c} \sim 1-\frac{1}{1+0.2 K K^{2}}$. For fish with disabled lateral line, $K=0$, we find $U_{c} \sim l^{2}$. In both cases, the model predicts that $U_{c}$ is larger for fish with larger body length. 
Table 2. Relevant publications on fish rheotaxis in the absence of visual cues, identified through literature review.

\begin{tabular}{|c|c|c|c|c|c|c|c|}
\hline \multirow{2}{*}{ Reference } & \multicolumn{2}{|c|}{ Fish } & \multirow{2}{*}{$\begin{array}{l}\text { Swimming } \\
\text { domain }\end{array}$} & \multicolumn{2}{|c|}{ Flow properties } & \multirow{2}{*}{ †Sensory cues } & \multirow{2}{*}{$\begin{array}{l}\text { Rheotaxis } \\
\text { threshold speed }\end{array}$} \\
\hline & Species & Length & & Flow speed & Flow gradient & & \\
\hline $\begin{array}{l}\text { Bak-Coleman et al. } \\
\text { (2013) }\end{array}$ & $\begin{array}{l}\text { Giant danio } \\
\text { (Devario } \\
\text { aequipinnatus) }\end{array}$ & $6.0-7.3 \mathrm{~cm}$ & $\begin{array}{l}\text { Flow tank of } \\
25 \times 25 \times 25 \mathrm{~cm} \\
(L \times h \times W)\end{array}$ & 0,3 , and $7 \mathrm{~cm} / \mathrm{s}$ & $\begin{array}{l}\operatorname{Re} \sim 7500 \text { at } \mathrm{LL}+\text { threshold } \\
\text { speed; flow gradient } \\
\text { expected to be small near } \\
\text { center of tank }\end{array}$ & $\mathrm{LL}+/ \mathrm{LL}-$ & $\leq 3 \mathrm{~cm} / \mathrm{s}$ \\
\hline $\begin{array}{l}\text { Bak-Coleman and } \\
\text { Coombs (2014) }\end{array}$ & $\begin{array}{l}\text { blind cavefish } \\
\text { (Astyanax } \\
\text { mexicanus) }\end{array}$ & $4.2-5.0 \mathrm{~cm}$ & $\begin{array}{l}\text { Flow tank of } \\
25 \times 25 \times 25 \mathrm{~cm} \\
(L \times h \times W)\end{array}$ & $\begin{array}{c}0,1,2,3,4,7, \text { and } \\
8 \mathrm{~cm} / \mathrm{s}\end{array}$ & $\begin{array}{l}\mathrm{Re} \sim 2000 \text { at } \mathrm{LL}+\text { threshold } \\
\text { speed; flow gradient } \\
\text { expected to be small near } \\
\text { center of tank }\end{array}$ & $\begin{array}{l}\text { LL+/LL-; fish } \\
\text { made } \\
\text { transient } \\
\text { contacts with } \\
\text { substrate }\end{array}$ & $\begin{array}{l}\mathrm{LL}+: 0.90 \mathrm{~cm} / \mathrm{s} \\
\mathrm{LL}-: 0.54 \mathrm{~cm} / \mathrm{s}\end{array}$ \\
\hline $\begin{array}{l}\text { *Baker and Mont- } \\
\text { gomery (1999) }\end{array}$ & $\begin{array}{l}\text { blind cavefish } \\
\text { (Astyanax } \\
\text { fasciatus) }\end{array}$ & $4-7 \mathrm{~cm}$ & $\begin{array}{l}\text { Flow tank of } \\
51 \times 9 \times 20 \mathrm{~cm} \\
(L \times h \times W)\end{array}$ & $0,2,3,5,9,16 \mathrm{~cm} / \mathrm{s}$ & $\begin{array}{l}\operatorname{Re} \sim 2000 \text { at } \mathrm{LL}+\text { threshold } \\
\text { speed; flow gradient } \\
\text { expected to be small near } \\
\text { center of tank }\end{array}$ & $\begin{array}{l}\mathrm{LL}+/ \mathrm{LL}-; \\
\text { tactile senses }\end{array}$ & $\begin{array}{l}\mathrm{LL}+: 2-3 \mathrm{~cm} / \mathrm{s} \\
\mathrm{LL}-:=9-16 \mathrm{~cm} / \mathrm{s}\end{array}$ \\
\hline $\begin{array}{l}\text { Elder and Coombs } \\
\text { (2015) }\end{array}$ & $\begin{array}{l}\text { Mexican tetras } \\
\text { (Astyanax } \\
\text { mexicanus) }\end{array}$ & $8.3 \mathrm{~cm}$ & $\begin{array}{l}\text { Flow tank of } \\
25 \times 25 \times 25 \mathrm{~cm} \\
(L \times h \times W)\end{array}$ & $\begin{array}{c}0,1,2,4,7 \text {, and } \\
12 \mathrm{~cm} / \mathrm{s}\end{array}$ & $\begin{array}{l}\operatorname{Re} \sim 5000 \text { at threshold } \\
\text { speed; flow gradient } \\
\text { expected to be small near } \\
\text { center of tank }\end{array}$ & $\mathrm{LL}+/ \mathrm{LL}-$ & $\begin{array}{l}\sim 2 \mathrm{~cm} / \mathrm{s} \text { for } \mathrm{LL}+ \\
\text { and } \mathrm{LL}-\end{array}$ \\
\hline Kulpa et al. (2015) & $\begin{array}{l}\text { blind cavefish } \\
\text { (Astyanax } \\
\text { mexicanus) }\end{array}$ & $4.4-5.3 \mathrm{~cm}$ & $\begin{array}{l}\text { Flow tank of } \\
25 \times 25 \times 10 \mathrm{~cm} \\
(L \times h \times W)\end{array}$ & $\begin{array}{l}\text { Maximum speed } \\
\text { of } 8 \mathrm{~cm} / \mathrm{s}\end{array}$ & $\begin{array}{l}\text { Jet flow across center of } \\
\text { tank; flow gradient } \\
\text { expected to be large }\end{array}$ & $\mathrm{LL}+/ \mathrm{LL}-$ & $\leq 8 \mathrm{~cm} / \mathrm{s}$ \\
\hline ¥Lyon (1904) & blind Fundulus & unspecified & $\begin{array}{l}\text { Trough with } \\
\text { unspecified } \\
\text { dimensions; } \\
\text { tideway } \\
\text { leading to } \\
\text { pond }\end{array}$ & $\begin{array}{l}\text { "not too strong } \\
\text { current" in trough } \\
\text { and current with } \\
\text { "more or less eddy } \\
\text { and irregularity" in } \\
\text { tideway }\end{array}$ & $\begin{array}{l}\text { Flow gradient expected to } \\
\text { be small }\end{array}$ & $\begin{array}{l}\mathrm{LL}+\text {; some fish } \\
\text { gained tactile } \\
\text { senses }\end{array}$ & $\begin{array}{l}\text { Not measured; } \\
\text { rheotaxis elicited } \\
\text { only by tactile } \\
\text { cues }\end{array}$ \\
\hline ¥Lyon (1904) & blind Fundulus & unspecified & $\begin{array}{l}\text { Trough with } \\
\text { unspecified } \\
\text { dimensions }\end{array}$ & $\begin{array}{l}\text { flow "gushing } \\
\text { rather violently" }\end{array}$ & $\begin{array}{l}\text { Jet flow; flow gradient } \\
\text { expected to be large }\end{array}$ & LL+ & $\begin{array}{l}\text { Not measured; } \\
\text { rheotaxis elicited } \\
\text { by flow }\end{array}$ \\
\hline $\begin{array}{l}\text { *Montgomery et al. } \\
\text { (1997) }\end{array}$ & $\begin{array}{l}\text { blind cavefish } \\
\text { (Astyanax } \\
\text { fasciatus) }\end{array}$ & $4-7 \mathrm{~cm}$ & $\begin{array}{c}{ }^{\S} \text { Flow tank of } \\
51 \times 9 \times 20 \mathrm{~cm} \\
(L \times h \times W)\end{array}$ & $\begin{array}{c}0,2,3,5,9, \text { and } \\
16 \mathrm{~cm} / \mathrm{s}\end{array}$ & $\begin{array}{l}\operatorname{Re} \sim 2000 \text { at } \mathrm{LL}+\text { threshold } \\
\text { speed; flow gradient } \\
\text { expected to be small near } \\
\text { center of tank }\end{array}$ & $\begin{array}{l}\mathrm{LL}+/ \mathrm{LL}-; \\
\text { tactile senses }\end{array}$ & $\begin{array}{l}\mathrm{LL}+: 2-3 \mathrm{~cm} / \mathrm{s} \\
\mathrm{LL}-: 9-16 \mathrm{~cm} / \mathrm{s}\end{array}$ \\
\hline
\end{tabular}


Table 2. Relevant publications on fish rheotaxis in the absence of visual cues, identified through literature review.

\begin{tabular}{|c|c|c|c|c|c|c|c|}
\hline \multirow{2}{*}{ Reference } & \multicolumn{2}{|c|}{ Fish } & \multirow{2}{*}{$\begin{array}{l}\text { Swimming } \\
\text { domain }\end{array}$} & \multicolumn{2}{|c|}{ Flow properties } & \multirow{2}{*}{ †Sensory cues } & \multirow{2}{*}{$\begin{array}{c}\text { Rheotaxis } \\
\text { threshold speed }\end{array}$} \\
\hline & Species & Length & & Flow speed & Flow gradient & & \\
\hline Oteiza et al. (2017) & $\begin{array}{c}\text { zebrafish } \\
\text { (Danio rerio) } \\
\text { larva 5-7 days } \\
\text { post } \\
\text { fertilization } \\
\text { (dpf) }\end{array}$ & unspecified & $\begin{array}{c}13 \mathrm{~cm} \text {-long } \\
\text { circular tube } \\
\text { with diameter } \\
1.27-4.76 \mathrm{~cm}\end{array}$ & $0.2-0.8 \mathrm{~cm} / \mathrm{s}$ & $\begin{array}{l}\text { Low to high flow gradients } \\
\text { identified through particle } \\
\text { image velocimetry }\end{array}$ & $\mathrm{LL}+/ \mathrm{LL}-$ & $\begin{array}{l}\mathrm{LL}+\text { : rheotaxis } \\
\text { observed as low } \\
\text { as } 0.2 \mathrm{~cm} / \mathrm{s}\end{array}$ \\
\hline Peimani et al. (2017) & $\begin{array}{c}\text { zebrafish } \\
\text { (Danio rerio) } \\
\text { larva 5-7 dpf }\end{array}$ & $\begin{array}{l}\text { estimated } \\
\sim 0.35 \mathrm{~cm}\end{array}$ & $\begin{array}{c}\text { Flow channel } \\
\text { of } 63.3 \times 1.6 \times \\
0.55 \mathrm{~mm} \\
(L \times h \times W)\end{array}$ & $0.95-3.8 \mathrm{~cm} / \mathrm{s}$ & $\begin{array}{l}\mathrm{Re} \sim 10 \text { at threshold speed; } \\
\text { flow gradient expected to } \\
\text { be large }\end{array}$ & $\mathrm{LL}+$ & $0.95 \mathrm{~cm} / \mathrm{s}$ \\
\hline Suli et al. (2012) & $\begin{array}{l}\text { zebrafish } \\
\text { (Danio rerio) } \\
\text { larva } 5 \mathrm{dpf}\end{array}$ & $\sim 0.33 \mathrm{~cm}$ & $\begin{array}{l}\text { Flume of } \\
110 \times 3.7 \times 2.8 \mathrm{~cm} \\
(L \times h \times W)\end{array}$ & $0.075,0.15,0.2 \mathrm{~cm} / \mathrm{s}$ & $\begin{array}{l}\operatorname{Re}<75 \text {; flow gradient } \\
\text { expected to be large }\end{array}$ & $\mathrm{LL}+/ \mathrm{LL}-$ & Not quantified \\
\hline $\begin{array}{l}\text { Van Trump and } \\
\text { McHenry (2013) }\end{array}$ & $\begin{array}{l}\text { blind Mexican } \\
\text { cavefish } \\
\text { (Astyanax } \\
\text { fasciatus) }\end{array}$ & $3-7 \mathrm{~cm}$ & $\begin{array}{c}\text { Cylindrical } \\
\text { channel of } \\
150 \times 11 \mathrm{~cm} \\
(L \times D)\end{array}$ & $\begin{array}{c}0,1,2,4,6,8,10 \\
13,16 \mathrm{~cm} / \mathrm{s}\end{array}$ & $\begin{array}{l}\text { Re }>2000 \text { at threshold } \\
\text { speed; flow gradient } \\
\text { expected to be small near } \\
\text { center of tank }\end{array}$ & $\mathrm{LL}+/ \mathrm{LL}-$ & $2-4 \mathrm{~cm} / \mathrm{s}$ \\
\hline
\end{tabular}

$538 \quad$ LL+: lateral line enabled; LL-: lateral line disabled

$539 *$ Data are extracted from the same set of experiments

540 ₹ Two experiments are considered from the same paper

541 \& Data are from Baker and Montgomery (1999) 


\section{Estimation of model parameters}

543 In a typical experimental setup on rheotaxis, the width of the channel, $h$, is on the order of three 544 to ten times the body length of the animal, $l$. For example, experiments from Elder and Coombs 545 (2015) on Mexican tetras of $l=8.3 \mathrm{~cm}$ were conducted in a channel with $h=25 \mathrm{~cm}$. Similarly, in

Table 3. Estimation of model parameters from data in the literature.

\begin{tabular}{|c|c|c|c|c|c|}
\hline Reference & $\rho$ & $\epsilon$ & $\alpha$ & $\kappa$ & $\beta$ \\
\hline $\begin{array}{l}\text { Bak-Coleman et al. } \\
(2013)\end{array}$ & $\sim 0.05$ & {$\left[10^{-2}, 10^{-1}\right]$} & {$[0,0.17]$} & - & - \\
\hline $\begin{array}{l}\text { Bak-Coleman and } \\
\text { Coombs (2014) }\end{array}$ & $\sim 0.04$ & {$\left[10^{-2}, 10^{-1}\right]$} & {$[0,0.16]$} & $\sim 0$ & {$[0,100]$} \\
\hline $\begin{array}{l}\text { Baker and Montgomery } \\
\text { (1999) and Montgomery } \\
\text { et al. (1997) }\end{array}$ & $\sim 0.1$ & {$\left[10^{-2}, 10^{-1}\right]$} & ${ }^{\dagger}[0,0.32]$ & {$[2,7]$} & {$[0,256]$} \\
\hline Elder and Coombs (2015) & $\sim 0.066$ & {$\left[10^{-2}, 10^{-1}\right]$} & $\dagger[0,0.24]$ & $\sim 0$ & {$[0,55]$} \\
\hline Kulpa et al. (2015) & $\sim 0.04$ & $\begin{array}{c}\sim 1 \text { near center } \\
\text { of jet }\end{array}$ & $\sim 1.3$ & - & - \\
\hline Oteiza et al. (2017) & {$[0.018,0.066]$} & {$[0.20,0.82]$} & - & - & - \\
\hline Peimani et al. (2017) & $\sim 0.044$ & $\sim 1$ & - & - & - \\
\hline Suli et al. (2012) & $\sim 0.018$ & {$[0.1,1]$} & - & - & - \\
\hline $\begin{array}{l}\text { Van Trump and McHenry } \\
\text { (2013) }\end{array}$ & {$[0.055,0.127]$} & {$\left[10^{-2}, 10^{-1}\right]$} & $\dagger[0,0.32]$ & $\sim 0$ & {$[0,106]$} \\
\hline
\end{tabular}
the experiments on adult zebrafish from Burbano- $L$ and Porfiri (2021), $l=3.6 \mathrm{~cm}$ and $h=13.8 \mathrm{~cm}$ and in the experiments on zebrafish larvae from Oteiza et al. (2017), $l=4.2 \mathrm{~mm}$ (inferred from the animals' age) and $h=1.27-4.76 \mathrm{~cm}$. The distance between the vortices simulating a fish, $r_{0}$, should be on the order of a tail beat, which has a typical value of $0.2 l$ (Gazzola et al.,2014). As a result, it is tenable to assume that $\rho^{2}$ is between $10^{-4}$ and $10^{-2}$.

A safe estimation of the velocity of the animal in the absence of the background flow, $v_{0}$, would be on the order of few body lengths per second (Gazzola et al., 2014). The speed used for the background flow across experiments, $U_{0}$, tend to be of the same order as the magnitude of $v_{0}$, leaning toward values close to one body length per second (Coombs et al., 2020). For instance, data on zebrafish from Burbano-L and Porfiri (2021) suggest $v_{0}=5.7 \mathrm{~cm} \mathrm{~s}^{-1}$ and $U_{0}=3.2 \mathrm{~cm} \mathrm{~s}^{-1}$. The estimation of the non-dimensional parameter $\epsilon$ associated with the shear in the flow is more difficult, since data on the velocity profiles are seldom reported. That being said, for channel flow of sufficiently high Reynolds number, the velocity profile in the channel is expected to be blunt, approximating a uniform flow profile near the channel center (White, 1974). Thus, it is tenable to treat $\epsilon$ as a small parameter, between $10^{-2}$ and $10^{-1}$. For flow of low Reynolds number (Oteiza et al., 2017) $(\mathrm{Re}<100)$, the velocity gradient in the channel has been observed to be large, corresponding to $\epsilon$ values in the range of $10^{-1}$ and 1 . By combining these estimations, we propose that $\alpha$ ranges between 0 and 1 .

An estimation of $\kappa$ is difficult to offer, whereby feedback from the lateral line has only been included in few studies (Oteiza et al., 2017; Burbano-L and Porfiri, 2021; Colvert and Kanso, 2016; Chicoli et al., 2015). Using the data-driven model from Burbano-L and Porfiri (2021), it is tenable to assume values on the order of $10^{1}$ for individuals showing high rheotactic performance. This gain can also be estimated by comparing the threshold speeds of fish with and without the lateral line, through $\frac{U_{c}(\mathrm{LL}-)}{U_{c}(\mathrm{LL}+)}=1+\kappa$, according to (11). The significant increase in the threshold speed following lateral line ablation in Baker and Montgomery (1999) indicates that $\kappa \in[2,7]$, while the indistinguishable threshold speed between LL+ and LL- fish in a few other studies (Bak-Coleman and Coombs, 2014; Elder and Coombs, 2015; Van Trump and McHenry, 2013) may suggest that $\kappa \sim 0$. In Table 3, we summarize the model parameters identified from data in the experimental studies comprising Tables 1 and 2.

$55+\mathrm{LL}+$ cavefish swimming speed $v_{0} \sim 5 \mathrm{~cm} / \mathrm{s}$ in zero background flow in Bak-Coleman and Coombs (2014) is used to estimate $\alpha$ 


\section{Acknowledgments}

The authors acknowledge financial support from the National Science Foundation under Grant No. CMMI-1901697. The authors acknowledge Alain Boldini and Simone Macrì for useful discussions.

\section{Author Contributions}

M.P. and S.D.P. conceived the study. M.P. and S.D.P. developed the theoretical model and performed data analysis. P.Z. conducted the literature review and performed the model validation. M.P. and S.D.P. wrote a first draft of the manuscript, which was consolidated in its present form by all the authors.

\section{Competing Interests}

The authors declare that they have no competing financial interests.

\section{Data and materials availability}

The authors declare that the data supporting the findings of this study are available within the paper. The Mathematica notebook used to derive the governing equations, study the planar dynamical, and generate associated figures are also available at https://github.com/dynamicalsystemslaboratory/

Rheotaxis.

\section{References}

Aiello BR, Olsen AM, Mathis CE, Westneat MW, Hale ME. Pectoral fin kinematics and motor patterns are shaped by fin ray mechanosensation during steady swimming in Scarus quoyi. Journal of Experimental Biology. 2020; 223(2). doi: 10.1242/jeb.211466.

Akaike H. Information theory and an extension of the maximum likelihood principle. In: Selected Papers of Hirotugu Akaike Springer; 1998.p. 199-213.

Aoki I. A simulation study on the schooling mechanism in fish. Bulletin of the Japanese Society of Scientific Fisheries (Japan). 1982; 48(8):1081-1088.

Arnold GP. The Reactions of the Plaice (Pleuronectes Platessa L.) to Water Currents. Journal of Experimental Biology. 1969; 51(3):681-697. doi: 10.1242/jeb.51.3.681.

Arnold G. Rheotropism in fishes. Biological Reviews. 1974; 49(4):515-576.

Ashraf I, Bradshaw H, Ha TT, Halloy J, Godoy-Diana R, Thiria B. Simple phalanx pattern leads to energy saving in cohesive fish schooling. Proceedings of the National Academy of Sciences. 2017; 114(36):9599-9604.

Bak-Coleman J, Coombs S. Sedentary behavior as a factor in determining lateral line contributions to rheotaxis. Journal of Experimental Biology. 2014; 217(13):2338-2347. doi: 10.1242/jeb.102574.

Bak-Coleman J, Paley DA, Coombs S, et al. The spatiotemporal dynamics of rheotactic behavior depends on flow speed and available sensory information. Journal of Experimental Biology. 2013; 216(21):4011-4024.

Baker CF, Montgomery JC. The sensory basis of rheotaxis in the blind Mexican cave fish, Astyanax fasciatus. Journal of Comparative Physiology A. 1999; 184(5):519-527. doi: 10.1007/s003590050351.

Bakker P. Some Elements Of The Qualitative Theory Of Differential Equations. In: Bifurcations in Flow Patterns Springer; 1991.p. 1-41.

Batchelor GK. An Introduction to Fluid Dynamics. Cambridge Mathematical Library, Cambridge University Press; 2000. doi: 10.1017/CBO9780511800955.

Becker AD, Masoud H, Newbolt JW, Shelley M, Ristroph L. Hydrodynamic schooling of flapping swimmers. Nature Communications. 2015; 6(1):1-8.

Blevins RD. Flow-induced vibration. New York. 1977; .

Brawn VM. Underwater Television Observations of the Swimming Speed and Behaviour of Captive Herring. Journal of the Fisheries Research Board of Canada. 1960; 17(5):689-698. doi: 10.1139/f60-054. 
Burbano-L DA, Porfiri M. Modeling multi-sensory feedback control of zebrafish in a flow. PLoS Computational Biology. 2021; 17(1):e1008644.

Butail S, Mwaffo V, Porfiri M. Model-free information-theoretic approach to infer leadership in pairs of zebrafish. Physical Review E. 2016; 93(4):042411.

Calovi DS, Lopez U, Ngo S, Sire C, Chaté H, Theraulaz G. Swarming, schooling, milling: phase diagram of a data-driven fish school model. New Journal of Physics. 2014; 16(1):015026.

Calovi DS, Lopez U, Schuhmacher P, Chaté H, Sire C, Theraulaz G. Collective response to perturbations in a data-driven fish school model. Journal of The Royal Society Interface. 2015; 12(104):20141362.

Chapman JW, Klaassen RH, Drake VA, Fossette S, Hays GC, Metcalfe JD, Reynolds AM, Reynolds DR, Alerstam T. Animal orientation strategies for movement in flows. Current Biology. 2011; 21(20):R861-R870.

Chicoli A, Bak-Coleman J, Coombs S, Paley D. Rheotaxis performance increases with group size in a coupled phase model with sensory noise. The European Physical Journal Special Topics. 2015; 224(17):3233-3244.

Colgate JE, Lynch KM. Mechanics and control of swimming: a review. IEEE Journal of Oceanic Engineering. 2004; 29(3):660-673. doi: 10.1109/JOE.2004.833208.

Colvert B, Kanso E. Fishlike rheotaxis. Journal of Fluid Mechanics. 2016; 793:656.

Coombs S, Bak-Coleman J, Montgomery J. Rheotaxis revisited: a multi-behavioral and multisensory perspective on how fish orient to flow. Journal of Experimental Biology. 2020; 223(23).

Couzin ID, Krause J, Franks NR, Levin SA. Effective leadership and decision-making in animal groups on the move. Nature. 2005; 433(7025):513-516.

Dabiri JO. How fish feel the flow. Nature. 2017; 547(7664):406-407.

Davidson VM. Salmon and Eel Movement in Constant Circular Current. Journal of the Fisheries Research Board of Canada. 1949; 7c(7):432-448. doi: 10.1139/f47-035.

De Bie J, Manes C, Kemp PS. Collective behaviour of fish in the presence and absence of flow. Animal Behaviour. 2020; 167:151-159.

Edmundson E, Everest FE, Chapman DW. Permanence of Station in Juvenile Chinook Salmon and Steelhead Trout. Journal of the Fisheries Research Board of Canada. 1968; 25(7):1453-1464. doi: 10.1139/f68-126.

Elder J, Coombs S. The influence of turbulence on the sensory basis of rheotaxis. Journal of Comparative Physiology A. 2015; 201(7):667-680.

Elliott J. Daily fluctuations of drift invertebrates in a Dartmoor stream. Nature. 1965; 205(4976):1127-1129. doi: 10.1038/2051127c0.

Filella A, Nadal F, Sire C, Kanso E, Eloy C. Model of collective fish behavior with hydrodynamic interactions. Physical Review Letters. 2018; 120(19):198101.

Fraser NHC, Metcalfe NB, Thorpe JE. Temperature-dependent switch between diurnal and nocturnal foraging in salmon. Proceedings of the Royal Society of London Series B: Biological Sciences. 1993; 252(1334):135-139. doi: 10.1098/rspb.1993.0057.

Friedland B. Control system design: an introduction to state-space methods. Courier Corporation; 2012.

Gautrais J, Ginelli F, Fournier R, Blanco S, Soria M, Chaté H, Theraulaz G. Deciphering interactions in moving animal groups. PLOS Computational Biology. 2012; 8(9):e1002678.

Gautrais J, Jost C, Soria M, Campo A, Motsch S, Fournier R, Blanco S, Theraulaz G. Analyzing fish movement as a persistent turning walker. Journal of Mathematical Biology. 2009; 58(3):429-445.

Gazzola M, Argentina M, Mahadevan L. Scaling macroscopic aquatic locomotion. Nature Physics. 2014; 10(10):758-761.

Gazzola M, Argentina M, Mahadevan L. Gait and speed selection in slender inertial swimmers. Proceedings of the National Academy of Sciences. 2015; 112(13):3874-3879. 
Gazzola M, Tchieu AA, Alexeev D, de Brauer A, Koumoutsakos P. Learning to school in the presence of hydrodynamic interactions. Journal of Fluid Mechanics. 2016; 789:726-749.

Gibson RJ. Some Factors Influencing the Distributions of Brook Trout and Young Atlantic Salmon. Journal of the Fisheries Research Board of Canada. 1966; 23(12):1977-1980. doi: 10.1139/f66-185.

Hardy AR, Steinworth BM, Hale ME. Touch sensation by pectoral fins of the catfish Pimelodus pictus. Proceedings of the Royal Society B: Biological Sciences. 2016; 283(1824):20152652. doi: 10.1098/rspb.2015.2652.

Herbert-Read JE, Krause S, Morrell L, Schaerf T, Krause J, Ward A. The role of individuality in collective group movement. Proceedings of the Royal Society B: Biological Sciences. 2013; 280(1752):20122564.

Herbert-Read JE, Perna A, Mann RP, Schaerf TM, Sumpter DJ, Ward AJ. Inferring the rules of interaction of shoaling fish. Proceedings of the National Academy of Sciences. 2011; 108(46):18726-18731.

Hoar WS. The Behaviour of Juvenile Pacific Salmon, with Particular Reference to the Sockeye (Oncorhynchus nerka). Journal of the Fisheries Research Board of Canada. 1954; 11(1):69-97. doi: 10.1139/f54-009.

Hoare D, Reeves P, Krause J. Positioning behaviour in roach shoals: the role of body length and nutritional state. Behaviour. 1998; 135(8):1031-1039.

Kalueff AV, Gebhardt M, Stewart AM, Cachat JM, Brimmer M, Chawla JS, Craddock C, Kyzar EJ, Roth A, Landsman S, et al. Towards a comprehensive catalog of zebrafish behavior 1.0 and beyond. Zebrafish. 2013; 10(1):7086.

Kanso E, Michelin S. Phoretic and hydrodynamic interactions of weakly confined autophoretic particles. The Journal of Chemical Physics. 2019; 150(4):044902.

Kanso E, Tsang ACH. Dipole models of self-propelled bodies. Fluid Dynamics Research. 2014; 46(6):061407.

Karakaya M, Macrì S, Porfiri M. Behavioral teleporting of individual ethograms onto inanimate robots: experiments on social interactions in live zebrafish. iScience. 2020; 23(8):101418.

Kato S, Nakagawa T, Ohkawa M, Muramoto K, Oyama O, Watanabe A, Nakashima H, Nemoto T, Sugitani K. A computer image processing system for quantification of zebrafish behavior. Journal of Neuroscience Methods. 2004; 134(1):1-7.

Katz Y, Tunstrøm K, loannou CC, Huepe C, Couzin ID. Inferring the structure and dynamics of interactions in schooling fish. Proceedings of the National Academy of Sciences. 2011; 108(46):18720-18725.

Krause J, Hoare D, Krause S, Hemelrijk C, Rubenstein D. Leadership in fish shoals. Fish and Fisheries. 2000; 1(1):82-89.

Kulpa M, Bak-Coleman J, Coombs S. The lateral line is necessary for blind cavefish rheotaxis in non-uniform flow. Journal of Experimental Biology. 2015; 218(10):1603-1612. doi: 10.1242/jeb.119537.

Laan A, Gil de Sagredo R, de Polavieja GG. Signatures of optimal control in pairs of schooling zebrafish. Proceedings of the Royal Society B: Biological Sciences. 2017; 284(1852):20170224.

Ladu F, Butail S, Macrí S, Porfiri M. Sociality modulates the effects of ethanol in zebra fish. Alcoholism: Clinical and Experimental Research. 2014; 38(7):2096-2104.

Landa JT. Bioeconomics of schooling fishes: selfish fish, quasi-free riders, and other fishy tales. Environmental Biology of Fishes. 1998; 53(4):353-364.

Larsson M. Why do fish school? Current Zoology. 2012; 58(1):116-128.

Lauder GV, Drucker EG. Forces, fishes, and fluids: hydrodynamic mechanisms of aquatic locomotion. Physiology. 2002; 17(6):235-240.

Liao JC. A review of fish swimming mechanics and behaviour in altered flows. Philosophical Transactions of the Royal Society B: Biological Sciences. 2007; 362(1487):1973-1993.

Lighthill SJ. Mathematical Biofluiddynamics. SIAM; 1975.

Lyon E. On rheotropism. I.- Rheotropism in fishes. American Journal of Physiology-Legacy Content. 1904; 12(2):149-161. 
McNaught DC, Hasler AD. Surface schooling and feeding behavior in the white bass, Roccus chrysops (rafinesque), in Lake Mendota. Limnology and Oceanography. 1961; 6(1):53-60.

Meinsma G. Elementary proof of the Routh-Hurwitz test. Systems \& Control Letters. 1995; 25(4):237-242.

Miller N, Gerlai R. From schooling to shoaling: patterns of collective motion in zebrafish (Danio rerio). PloS One. 2012; 7(11):e48865.

Miller NY, Gerlai R. Shoaling in zebrafish: what we don't know. Reviews in the Neurosciences. 2011; 22(1):1725.

Milne-Thomson LM. Theoretical Hydrodynamics. Courier Corporation; 1996.

Mogdans J. Sensory ecology of the fish lateral-line system: Morphological and physiological adaptations for the perception of hydrodynamic stimuli. Journal of Fish Biology. 2019; 95(1):53-72. doi: 10.1111/jfb.13966.

Montgomery JC, Baker CF. Lateral Line and Fish Behavior. In: Fritzsch B, editor. The Senses: A Comprehensive Reference, second ed. Oxford: Elsevier; 2020.p. 133-142. doi: 10.1016/B978-0-12-809324-5.24169-2.

Montgomery JC, Baker CF, Carton AG. The lateral line can mediate rheotaxis in fish. Nature. 1997; 389(6654):960-963. doi: 10.1038/40135.

Mwaffo V, Anderson RP, Butail S, Porfiri M. A jump persistent turning walker to model zebrafish locomotion. Journal of The Royal Society Interface. 2015; 12(102):20140884.

Mwaffo V, Zhang P, Cruz SR, Porfiri M. Zebrafish swimming in the flow: a particle image velocimetry study. Peer]. 2017; 5:e4041.

Nakayama S, Harcourt JL, Johnstone RA, Manica A. Initiative, personality and leadership in pairs of foraging fish. PLoS One. 2012; 7(5):e36606.

Nakayama S, Harcourt JL, Johnstone RA, Manica A. Who directs group movement? Leader effort versus follower preference in stickleback fish of different personality. Biology Letters. 2016; 12(5):20160207.

Needham PR, Jones AC. Flow, Temperature, Solar Radiation, and Ice in Relation to Activities of Fishes in Sagehen Creek, California. Ecology. 1959; 40(3):465-474. doi: 10.2307/1929764.

Newton PK. The N-vortex Problem: Analytical Techniques, vol. 145. Springer Science \& Business Media; 2011.

Orger MB, de Polavieja GG. Zebrafish behavior: opportunities and challenges. Annual Review of Neuroscience. 2017; 40:125-147.

Oteiza P, Odstrcil l, Lauder G, Portugues R, Engert F. A novel mechanism for mechanosensory-based rheotaxis in larval zebrafish. Nature. 2017; 547(7664):445-448.

Partridge B, Pitcher T. Evidence against a hydrodynamic function for fish schools. Nature. 1979; 279(5712):418419.

Pavlov DS, Tjurjukov SN. Reactions of dace to linear accelerations. Journal of Fish Biology. 1995; 46(5):768-774. doi: 10.1111/j.1095-8649.1995.tb01600.x.

Peimani AR, Zoidl G, Rezai P. A microfluidic device for quantitative investigation of zebrafish larvae's rheotaxis. Biomedical Microdevices. 2017; 19(4):1-6. doi: 10.1007/s10544-017-0240-x.

Perna A, Grégoire G, Mann RP. On the duality between interaction responses and mutual positions in flocking and schooling. Movement Ecology. 2014; 2(1):22.

Pikovsky A, Kurths J, Rosenblum M, Kurths J. Synchronization: a universal concept in nonlinear sciences, vol. 12. Cambridge university press; 2003.

Pita D, Moore BA, Tyrrell LP, Fernández-Juricic E. Vision in two cyprinid fish: implications for collective behavior. Peer]. 2015; 3:e1113.

Pitcher TJ. Shoaling and shoaling behaviour in fishes. Comparative Psychology: a Handbook Garland, New York. 1998; p. 748-760.

Reebs S. Influence of body size on leadership in shoals of golden shiners, Notemigonus crysoleucas. Behaviour. 2001; 138(7):797-809. 
Russell WMS, Burch RL. The principles of humane experimental technique. Methuen; 1959.

Sánchez-Rodríguez J, Raufaste C, Argentina M. A minimal model of self propelled locomotion. Journal of Fluids and Structures. 2020; 97:103071.

Saric WS, Reed HL, Kerschen EJ. Boundary-Layer Receptivity to Freestream Disturbances. Annual Review of Fluid Mechanics. 2002; 34(1):291-319.

Sastry S. Nonlinear Systems: Analysis, Stability, and Control, vol. 10. Springer Science \& Business Media; 2013.

Schneider H. Measuring agonistic behavior in zebrafish. In: Zebrafish Neurobehavioral Protocols Springer; 2011.p. 125-134.

Sfakiotakis M, Lane DM, Davies JBC. Review of fish swimming modes for aquatic locomotion. IEEE Journal of Oceanic Engineering. 1999; 24(2):237-252. doi: 10.1109/48.757275.

Suli A, Watson GM, Rubel EW, Raible DW. Rheotaxis in Larval Zebrafish Is Mediated by Lateral Line Mechanosensory Hair Cells. PLoS ONE. 2012; 7:1-6. doi: 10.1371/journal.pone.0029727.

Tankov P. Financial modelling with jump processes. CRC press; 2003.

Taylor GI. Analysis of the swimming of long and narrow animals. Proceedings of the Royal Society of London Series A Mathematical and Physical Sciences. 1952; 214(1117):158-183.

Tchieu AA, Kanso E, Newton PK. The finite-dipole dynamical system. Proceedings of the Royal Society A: Mathematical, Physical and Engineering Sciences. 2012; 468(2146):3006-3026.

Tchieu AA, Kanso E, Newton PK. The finite-dipole dynamical system. Proceedings of the Royal Society A: Mathematical, Physical and Engineering Sciences. 2012; 468(2146):3006-3026.

Van Trump WJ, McHenry MJ. The Lateral Line System is Not Necessary for Rheotaxis in the Mexican Blind Cavefish (Astyanax fasciatus). Integrative and Comparative Biology. 2013; 53(5):799-809. doi: 10.1093/icb/ict064.

Vicsek T, Zafeiris A. Collective motion. Physics Reports. 2012; 517(3-4):71-140.

Waters TF. Diurnal periodicity in the drift of stream invertebrates. Ecology. 1962; 43(2):316-320.

Webb PW. Kinematics of plaice, Pleuronectes platessa, and cod, Gadus morhua, swimming near the bottom. Journal of Experimental Biology. 2002; 205(14):2125-2134. doi: 10.1242/jeb.205.14.2125.

Weihs D. Hydromechanics of fish schooling. Nature. 1973; 241(5387):290-291.

White FM. Viscous Fluid Flow. McGraw-Hill; 1974.

Williamson CHK, Govardhan R. Vortex-Induced Vibrations. Annual Review of Fluid Mechanics. 2004; 36(1):413455.

Wiwchar LD, Gilbert MJ, Kasurak AV, Tierney KB. Schooling improves critical swimming performance in zebrafish (Danio rerio). Canadian Journal of Fisheries and Aquatic Sciences. 2018; 75(4):653-661.

Wu TYT. Hydromechanics of swimming propulsion. Part 1. Swimming of a two-dimensional flexible plate at variable forward speeds in an inviscid fluid. Journal of Fluid Mechanics. 1971; 46(2):337-355.

Zhang F, Lagor FD, Lei H, Tan X, Paley DA. Robotic fish. Mechanical Engineering. 2016; 138(03):S2-S5.

Zienkiewicz A, Barton D, Porfiri M, Di Bernardo M. Leadership emergence in a data-driven model of zebrafish shoals with speed modulation. The European Physical Journal Special Topics. 2015; 224(17):3343-3360.

Zienkiewicz A, Barton DA, Porfiri M, Di Bernardo M. Data-driven stochastic modelling of zebrafish locomotion. Journal of Mathematical Biology. 2015; 71(5):1081-1105.

Zienkiewicz AK, Ladu F, Barton DA, Porfiri M, Di Bernardo M. Data-driven modelling of social forces and collective behaviour in zebrafish. Journal of Theoretical Biology. 2018; 443:39-51. 


\section{Appendix 1}

\section{Complete expression for the velocity field caused by image dipoles}

The velocity field $\vec{u}_{f}=u_{f} \hat{i}+v_{f} \hat{j}$ at $\vec{r}$ induced by the single dipole at $\vec{r}_{f}$, given by the potential function in equation (1), is

$$
\begin{aligned}
& u_{f}\left(\vec{r}, \vec{r}_{f}, \theta_{f}\right)=r_{0}^{2} v_{0}\left(\frac{\left(\left(x-x_{f}\right)^{2}-\left(y-y_{f}\right)^{2}\right) \cos \theta_{f}+2\left(x-x_{f}\right)\left(y-y_{f}\right) \sin \theta_{f}}{\left(\left(x-x_{f}\right)^{2}+\left(y-y_{f}\right)^{2}\right)^{2}}\right), \\
& v_{f}\left(\vec{r}, \vec{r}_{f}, \theta_{f}\right)=r_{0}^{2} v_{0}\left(\frac{-\left(\left(x-x_{f}\right)^{2}-\left(y-y_{f}\right)^{2}\right) \sin \theta_{f}+2\left(x-x_{f}\right)\left(y-y_{f}\right) \cos \theta_{f}}{\left(\left(x-x_{f}\right)^{2}+\left(y-y_{f}\right)^{2}\right)^{2}}\right) .
\end{aligned}
$$

The potential function describing the image vortex system for a dipole in a channel presented in equation (3) can be simplified using Mathematica, yielding

$$
\begin{aligned}
\phi_{w}\left(\vec{r}, \vec{r}_{f}, \theta_{f}\right)=\frac{r_{0}^{2} v_{0}}{4}\left[4 \frac{\left(x-x_{f}\right) \cos \theta_{f}+\left(y-y_{f}\right) \sin \theta_{f}}{\left(x-x_{f}\right)^{2}+\left(y-y_{f}\right)^{2}}\right. & \\
& \left.-\frac{\pi e^{-i \theta_{f}}}{h}\left(e^{2 i \theta_{f}}\left(\operatorname{coth}(\pi A)+\operatorname{coth}\left(\pi B^{*}\right)\right)+\operatorname{coth}\left(\pi A^{*}\right)+\operatorname{coth}(\pi B)\right)\right],
\end{aligned}
$$

where $A=\left(\left(x-x_{f}\right)+i\left(y-y_{f}\right)\right) /(2 h), B=\left(\left(x-x_{f}\right)+i\left(y+y_{f}\right)\right) /(2 h), i=\sqrt{-1}$, and a superscript * indicates complex conjugate. The velocity field at $\vec{r}$ due to the walls, $\vec{u}_{w}=u_{w} \hat{i}+v_{w} \hat{j}$, is

$$
\begin{array}{r}
u_{w}=\frac{r_{0}^{2} v_{0}}{4}\left[\frac{\pi^{2} e^{-i \theta_{f}}}{2 h^{2}}\left(e^{2 i \theta_{f}}\left(\operatorname{csch}^{2} \pi A+\operatorname{csch}^{2} \pi B^{*}\right)+\operatorname{csch}^{2} \pi A^{*}+\operatorname{csch}^{2} \pi B\right)\right) \\
\left.+\frac{4 \cos \theta_{f}}{\left(x-x_{f}\right)^{2}+\left(y-y_{f}\right)^{2}}-\frac{8\left(x-x_{f}\right)\left(\left(x-x_{f}\right) \cos \theta_{f}+\left(y-y_{f}\right) \sin \theta_{f}\right)}{\left(\left(x-x_{f}\right)^{2}+\left(y-y_{f}\right)^{2}\right)^{2}}\right], \\
v_{w}=\frac{r_{0}^{2} v_{0}}{4}\left[\frac{i \pi^{2} e^{-i \theta_{f}}}{2 h^{2}}\left(e^{2 i \theta_{f}}\left(\operatorname{csch}^{2} \pi A-\operatorname{csch}^{2} \pi B^{*}\right)-\operatorname{csch}^{2} \pi A^{*}+\operatorname{csch}^{2} \pi B\right)\right) \\
\left.+\frac{4 \sin \theta_{f}}{\left(x-x_{f}\right)^{2}+\left(y-y_{f}\right)^{2}}-\frac{8\left(y-y_{f}\right)\left(\left(x-x_{f}\right) \cos \theta_{f}+\left(y-y_{f}\right) \sin \theta_{f}\right)}{\left(\left(x-x_{f}\right)^{2}+\left(y-y_{f}\right)^{2}\right)^{2}}\right] .
\end{array}
$$

Superimposing the velocity fields from the dipole and its images and setting $y=0$ (or $y=h$ ) yields $v_{f}+v_{w}=0$, thereby confirming that the walls of the channel are streamlines. 